\title{
Geomorphological evolution of landslides near an active normal fault in northern Taiwan, as revealed by lidar and unmanned aircraft system data
}

\author{
Kuo-Jen Chang ${ }^{1}$, Yu-Chang Chan ${ }^{2}$, Rou-Fei $\mathrm{Chen}^{3}$, and Yu-Chung Hsieh ${ }^{4}$ \\ ${ }^{1}$ Department of Civil Engineering, National Taipei University of Technology, Taipei, 10654, Taiwan R.O.C \\ ${ }^{2}$ Institute of Earth Sciences, Academia Sinica, Taipei, Taiwan R.O.C \\ ${ }^{3}$ Department of Geology, Chinese Culture University, Taipei, 11114, Taiwan R.O.C \\ ${ }^{4}$ Central Geological Survey, MOEA, Taipei, Taiwan R.O.C
}

Correspondence: Kuo-Jen Chang (epidote@ntut.edu.tw)

Received: 21 June 2017 - Discussion started: 3 July 2017

Revised: 3 January 2018 - Accepted: 29 January 2018 - Published: 5 March 2018

\begin{abstract}
Several remote sensing techniques, namely traditional aerial photographs, an unmanned aircraft system (UAS), and airborne lidar, were used in this study to decipher the morphological features of obscure landslides in volcanic regions and how the observed features may be used for understanding landslide occurrence and potential hazard. A morphological reconstruction method was proposed to assess landslide morphology based on the dome-shaped topography of the volcanic edifice and the nature of its morphological evolution. Two large-scale landslides in the Tatun volcano group in northern Taiwan were targeted to more accurately characterize the landslide morphology through airborne lidar and UAS-derived digital terrain models and images. With the proposed reconstruction method, the depleted volume of the two landslides was estimated to be at least $820 \pm 20 \times 10^{6} \mathrm{~m}^{3}$. Normal faulting in the region likely played a role in triggering the two landslides, because there are extensive geological and historical records of an active normal fault in this region. The subsequent geomorphological evolution of the two landslides is thus inferred to account for the observed morphological and tectonic features that are indicative of resulting in large and life-threatening landslides, as characterized using the recent remote sensing techniques.
\end{abstract}

\section{Introduction}

Landslides pose long-lasting threats to humans and their property and are detrimental to the environment in general. Therefore, many efforts have been made to assess landslide hazards and propose mitigation methods based on key landslide characteristics, including range and extent, volume, triggering mechanism, recurrence, and subsequent evolution. The overview of landslides provided by morphological analysis has been fundamental in improving the understanding of landslides. Several useful morphological characteristics have been proposed for identifying potential landslide sites (Varnes, 1978; IAEG, 1990; Guzzetti et al., 2012; Santangelo et al., 2015a, b; Bucci et al., 2016); these can be readily applied for landslide recognition and identification. Clayton et al. (1982) suggested a useful procedure for improving site investigations and methods. Such methods may facilitate the identification of landslide sites and subsequent analysis of landslides. However, before regional-scale landslide recognition and identification, informative morphological analysis must be performed, the results of which are dependent on the quality and precision of the dataset. Morphological analysis involving observation and identification methods, such as contour topographic maps, aerial photography, and remote sensing images, is considered an essential task in the early stages of landslide investigations (IAEG, 1990; Santangelo et al., 2015a, b).

The morphological features of relatively old landslides are often perturbed by surficial processes, such as weathering, 
erosion, and vegetation colonization. The limited precision of aerial photographs and satellite images in many cases prevents detailed analysis of old landslides. Landslide recurrence is a major concern in engineering projects because it reveals the evolution of a landslide and its potential activity. However, landslide recurrence at a specific site cannot be easily and precisely determined, primarily because of the lack of georeferenced historical records of recent landslides. Therefore, it is important to study landslides that date from an earlier period in the evolutionary history of an area.

Volume estimation is crucial for characterizing and understanding landslides. The cut-and-fill volumes of a landslide can be estimated using two digital terrain models (DTMs): one before the landslide and one thereafter (Chang et al., 2005; Chen et al., 2006; Chan et al., 2012; Hsieh et al., 2016). The information derived using the DTMs can facilitate the identification and estimation of landslide activity and evolution. However, estimating the volumes of an old landslide site is relatively challenging. A method for determining landslide volume is to reconstruct paleogeomorphology before a landslide, which requires regional detailed topographic data and reasonable methods of geomorphological reconstruction.

Large-scale landslides are common and frequently recurrent in volcanic regions. The study area, Jinshan, is part of a volcano group in the Taipei metropolitan area in northern Taiwan (Fig. 1). Two large-scale landslides have already been suggested by Chyi-Tyi Lee (Chyi-Tyi Lee, National Central University, personal communication, 1998) from LANDSAT images and $40 \mathrm{~m}$ grid digital terrain model of the region but without formal documentation in the literature. Because of a lack of relevant information, the details of these landslides are yet to be analyzed. In this study, due to recently developed high-resolution and high-precision airborne light detection and ranging (lidar) and unmanned aircraft system (UAS) datasets, we proposed feasible methods for evaluating landslides, particularly old landslides, by performing paleotopographic reconstruction based on several concepts and the hypothetical shape of the natural edifice of a stratovolcano. The reconstructed instances of paleotopography were evaluated using different tests and used in the subsequent landslide analysis, including analysis of the landslide volumes and morphological evolution. Moreover, the interactions of tectonics and surface processes, including normal faulting, riverbed incision, and river drainage formation, are discussed in the context of the old landslides to provide perspectives on the newly acquired detailed topography.

\section{Geological background}

Taiwan is situated on an active orogenic belt formed by oblique convergence between the Philippine Sea and Eurasian plates (Ho, 1986; Malavieille et al., 2002). Despite the ongoing collision in central and southern Taiwan, a postcollision extension regime has developed since the Plio-
Pleistocene in the northern part of this orogeny (Teng, 1996) and has generated volcanic activity both onshore and offshore in northern Taiwan (Wang et al., 1999). The study area is composed of late Paleogene to Neogene sedimentary rocks (Suppe, 1981; Ho, 1986). The belt is defined by a series of imbricated, trending NE-SW, west-vergent folds and faults (Fig. 1). The strata are composed of late Oligocene to Pleistocene sedimentary rocks and are overlain by the intruded Tatun volcano group.

The study area has two major faults: the Kanchiao Fault (KCF) and Jinshan Fault (JSF; Fig. 1). The stratigraphic separation of the $\mathrm{KCF}$ through thrusting is estimated to exceed $2000 \mathrm{~m}$. However, recent marine seismic survey data clearly indicate that the KCF is now a normal fault. The NE-SWtrending JSF, which is situated in the northeast of the Tatun volcano group around Jinshan, has an estimated throw of $3000 \mathrm{~m}$ by thrusting. The late Oligocene Wuchihshan Formation is juxtaposed against the late Miocene Nanchuang Formation. It dips over $50^{\circ}$ toward the southeast with a trend of $60^{\circ}$ east of north.

These NE-SW-trending thrust faults and folds were identified on land (Huang, 1988), and their offshore extents have been confirmed (Hsiao, 1997; Hsiao et al., 1998). Before a major orogenic movement, the tectonic setting in this area of Taiwan was dominated by normal faults and half-grabens (Hsiao, 1997; Hsiao et al., 1998). Faults in this region were reactivated by extensional rifting tectonics as compressional synorogenic fold-and-thrust tectonism during the late MioPliocene period. Postorogenic extension subsequently resulted in the kinematics of these faults reverting to their earlier normal faulting regime. Currently, the offshore structures in northeastern Taiwan are in an extensional regime once again. The JSF has thus reactivated and reverted to being a normal fault, now known as the Shanchiao Fault (SCF).

The extensional postorogenic tectonism resulted in extensive igneous activity that began at approximately $2.8-2.5 \mathrm{Ma}$ (Wang, 1989) and continued throughout the quaternary period (Wang, 1989; Tsao, 1994). These volcanic rocks overlie sedimentary rocks that range from being late Oligocene to early Pleistocene. To a certain extent, the sequence of eruption history can be interpreted by the geomorphological features, petrological characteristics, and geochemical signatures of the volcanic rocks (Wang, 1989; Song, 2000; Chen, 2003). In the Tatun volcano group and its immediate vicinity, most lava flows were dated using $\mathrm{K}$-Ar and fission-track dating methods, which provided ages ranging from 0.8 to $0.2 \mathrm{Ma}$ (Tsao, 1994; Song, 2000).

The Taipei Basin is situated on the other side of the Tatun Volcano and is composed of an asymmetric wedgeshaped half-graben, adjacent to the Linkou Tableland. Both the Linkou Tableland and the basement of the Taipei Basin share the same age of 0.4 Ma (Wei et al., 1998; Teng et al., 2001). The elevation difference between the Taipei Basin and Linkou Tableland is as much as $250 \mathrm{~m}$; at the same time, the depocenter of Taipei Basin is at least $700 \mathrm{~m}$ in depth near 

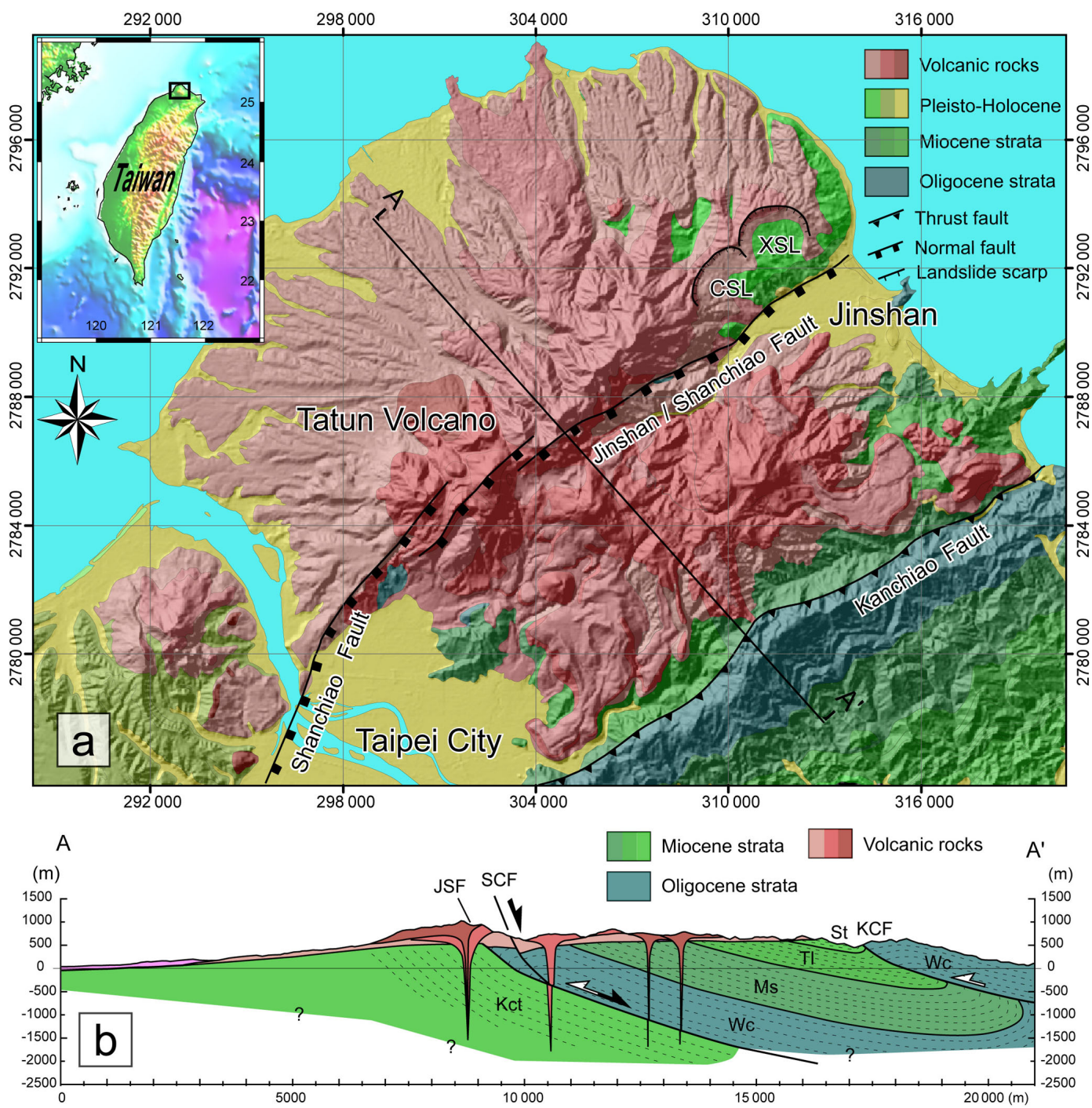

Figure 1. Geological and geomorphological map of the study area. (a) Geodynamic map of the island of Taiwan and its northern region, illustrating the regional tectonic structures and the geology near the sliding area. (b) Geological cross section of the study area, considered to be a region of imbricated, west-vergent, NE-SW-trending folds and thrusts in the Taiwan mountain belt. The compressive synorogenic and postorogenic activities separate the successive sedimentary rocks by the Kanchiao Fault (KCF), Jinshan Fault (JSF), and Shanchiao Fault (SCF, also known as the Jinshan Fault through normal faulting). Two landslide sites, the Xishi landslide (XSL) and Chinshui landslide (CSL), are denoted in the figure. The corresponding strata in the cross section, from bottom to top, are the late Oligocene Wuchihshan Formation (Wc), Miocene Mushan Formation (Ms), Miocene Taliao Formation (Tl), Miocene Shihti Formation (St), and Mio-Pliocene Kueichulin Formation (Kct).

the east margin of the Linkou Tableland that is separated by the Shanchiao normal fault (Teng, et al., 2001; Chen et al., 2007; Huang et al., 2007). This phenomenon reveals that the Shanchiao normal faulting resulted in at least $1000 \mathrm{~m}$ of throw of fault separation and contributed to the formation of Taipei Basin.

Recent studies reveal high tectonic activities of the Shanchiao normal fault, including geomorphic and geologic analysis by borehole investigation and record (Chen et al., 2007; Huang et al., 2007; Song et al., 2000), by the geodetic study (Yu et al., 1999), by the micromorphological study
(Chen et al., 2006), and by geomorphological study (Chang et al., 2010). The results show that the normal faulting slip rate is estimated between 8.2 and $1.8 \mathrm{~mm} \mathrm{yr}^{-1}$ in subsidence at different sites and in time intervals (Huang et al., 2007; Chen et al., 2010). Comparing with the Shanchiao Fault, however, the geometric property and tectonic activity of the Jinshan Fault have not been well resolved. But the Jinshan Fault certainly plays an important role for morphologic evolution within the study area. 


\section{Methods of data acquisition}

Geomorphologic analysis is one of the most fundamental tasks for the landslide study; however, it depends on the resolution and the quality of dataset used (Santangelo et al., 2015b). Classical techniques, such as aerial photography and stereoscope analysis, were used to extract detailed features of the target area (Santangelo et al., 2015b). Nevertheless, in Taiwan, heavy precipitation induced by the annual northeast monsoon easily modifies the landslide topography. On the other hand, the study region is situated within a national park and preserves dense forest very well. Both effects conceal detailed topography that is nearly impossible to study directly from aerial photographs and/or satellite images. Using traditional aerial photographs, satellite images, and $40 \mathrm{~m}$ grid digital elevation model (DEM), these analyses revealed common morphological features, including circular crowns and depletion zones bounded by topographic scarps on the upslope side within the study area. Two domains of different vegetation densities near the upper part of the sliding areas were observed to be affected by human activities. Two large circular landslides are marked as the northeastern Xishi landslide (XSL) and southwestern Chinshui landslide (CSL) denoted in Fig. 1. In the coarse DEM, the major geomorphic features of these two landslides are limited, with only two fractured circular crowns being visible. In consequence, a much higher resolution dataset is required to decipher more detailed landslide geomorphic components and for landslide investigation.

To acquire high-resolution topographic information, a homemade unmanned aircraft system (UAS) was integrated and used in this study. A UAS, commonly known as a drone, is an aircraft that flies autonomously and has many applications because of its low cost, convenience, and high resolution (Huang and Chang, 2014; Chen et al., 2015; FernandezGalarreta et al., 2015; Giordan et al., 2015; Tokarczyk, 2015; Bühler et al., 2016; Deffontaines et al., 2016). The UAS used in this study is a modified version of the Skywalker X8 deltawing aircraft. It is reinforced by carbon fiber rods and Kevlar fiber sheets. The UAS was launched by hand; it flew, captured photos, and then glided back to the ground. The whole process was conducted using a preprogrammed flight mission organized by a ground control system and remote controlled by the ground control station. The autopilot system was constructed and modified from the open-source APM (Ardupilot Mega 2.6 autopilot) firmware and open-source software Mission Planner, as transmitted through ground-air XBee telemetry.

To generate a high-resolution digital surface model (DSM), orthorectified mosaic images, and a true threedimensional (3-D) model, 1231 photos were captured by a Sony ILCE-QX1 camera mounted on the UAS. One flight mission of a total distance of $80 \mathrm{~km}$, duration of $90 \mathrm{~min}$, and $250 \mathrm{~m}$ of mean height above ground level was organized and implemented (Fig. 2). A total coverage area of $14.7 \mathrm{~km}^{2}$ with a $6.6 \mathrm{~cm}$ ground sampling distance was acquired from the flight mission. Repeated adjacent photographs were kept for at least $85 \%$ overlap and $45 \%$ sidelap. The datasets, including orthomosaic images, DSM, and true 3-D model, were generated and processed using ContextCapture and Pix4Dmapper with a grid spacing of $8.5 \mathrm{~cm}$. Figure $2 \mathrm{a}$ denotes the region of data acquisition by the UAS. The green and red points mark the waypoints of the flight mission and all photographs acquired, respectively. Figure $2 \mathrm{~b}$ and $\mathrm{c}$ demonstrate the 3-D scene of the study area simulated using the true 3-D model, where the crown area of one landslide was modified by human infrastructure.

On the other hand, the airborne lidar is an excellent tool for extracting the meter-scale surface features of landslides. Consequently, quantitative studies have been successfully conducted for delineating landslides; determining risks (Gritzner et al., 2001), landslide morphology (Glenn et al., 2006; Staley et al., 2006; Santangelo et al., 2015b), and activity (Chen et al., 2005; Chang et al., 2006); estimating cut-and-fill volumes (Chang et al., 2005; Chen et al., 2006; Chan et al., 2012; Hsieh et al., 2016); and performing geological mapping (Yeh et al., 2014). In this study, an Optech ALTM3070 apparatus was used to record the positions of the laser reflecting points with a rate of up to 71000 pulses per second when we conducted the Central Geological Survey project in 2005. In brief, the DSM is developed based on the first reflection of the laser scanning from the sorted point clouds that are reflected from vegetation or the tops of buildings. Consequently, the last reflection, occurring after the vegetation is penetrated, records the appearance of the ground surface. Processing the nearby reflecting signals can also eliminate buildings. Thus, the ground surface without vegetation and buildings, referred to as a digital terrain model (DTM), can be obtained.

In this study, the airborne lidar DSMs and DTMs were generated with a grid size of $2 \mathrm{~m}$ from the classified point clouds. The average densities of the point clouds for DSMs and DTMs were 3.63 and 0.75 points $\mathrm{m}^{-2}$, respectively. Compared with data measured using a differential global positioning system, the errors may vary according to differences in the terrains. For the study area, the mean errors, RMS, and standard deviation were 0.097, 0.126, and 0.081, respectively.

Before the morphological and tectonic analysis, the quality of the entire dataset (as shown in Fig. 2a) must be evaluated. Therefore, 20 ground control points used in this study were extracted from the airborne lidar dataset. The quality of the DSM was approximately $5 \mathrm{~cm}$ with a maximum error of $35 \mathrm{~cm}$ in the root-mean-square (RMS) deviation compared with that of the airborne lidar data for the open bare ground area, where the elevation of the DTM corresponds to that of the DSM, and there is neither vegetation nor buildings. Figures 2 and 3 provide some examples of the quality of both DEM and orthomosaic images of the study area. The morphological features of the ground surface based on the 

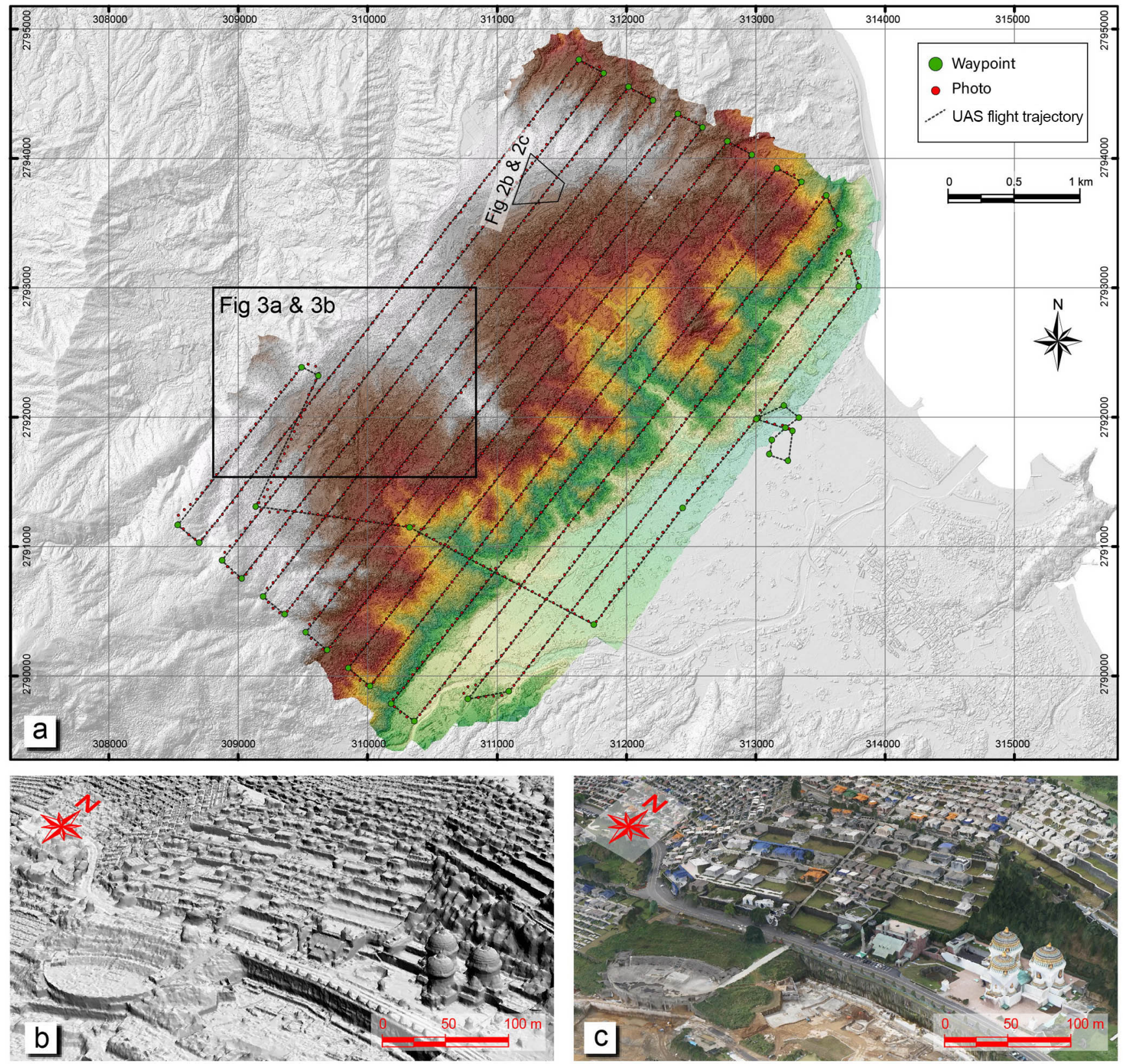

Figure 2. Data acquisition from an unmanned aircraft system flight mission. (a) DSM generated by the UAS for a total area of $14.7 \mathrm{~km}^{2}$ with a ground sampling distance of $6.6 \mathrm{~cm}$, where points and lines represent the positions and path of the flight mission, respectively, and the monotone gray area is the lidar DSM; (b) side view of the hillshaded true 3-D model; and (c) image draped onto the true 3-D model. The side views of (b) and (c) are captured at the same position and orientation.

acquired DEM and photographs were analyzed and accordingly interpreted.

The UAS images, which generate $8.5 \mathrm{~cm}$ pixel resolution in both the orthomosaic photo and DSM, distinguish clearly the ground and non-ground features, such as buildings and sparse vegetation. Moreover, this information is helpful for improving the airborne lidar data processing and point cloud classification.
Figure 3 presents images of the same area close to the southwestern CSL slide crowns obtained from different sources and highlights the resolution and application of different datasets. In the study area, two different landforms can be readily distinguished, i.e., dense forest and sparse vegetation regions resulting from human and agricultural development. The gentle slope and fractured volcanic rock mass provided a suitable environment for agriculture and habita- 

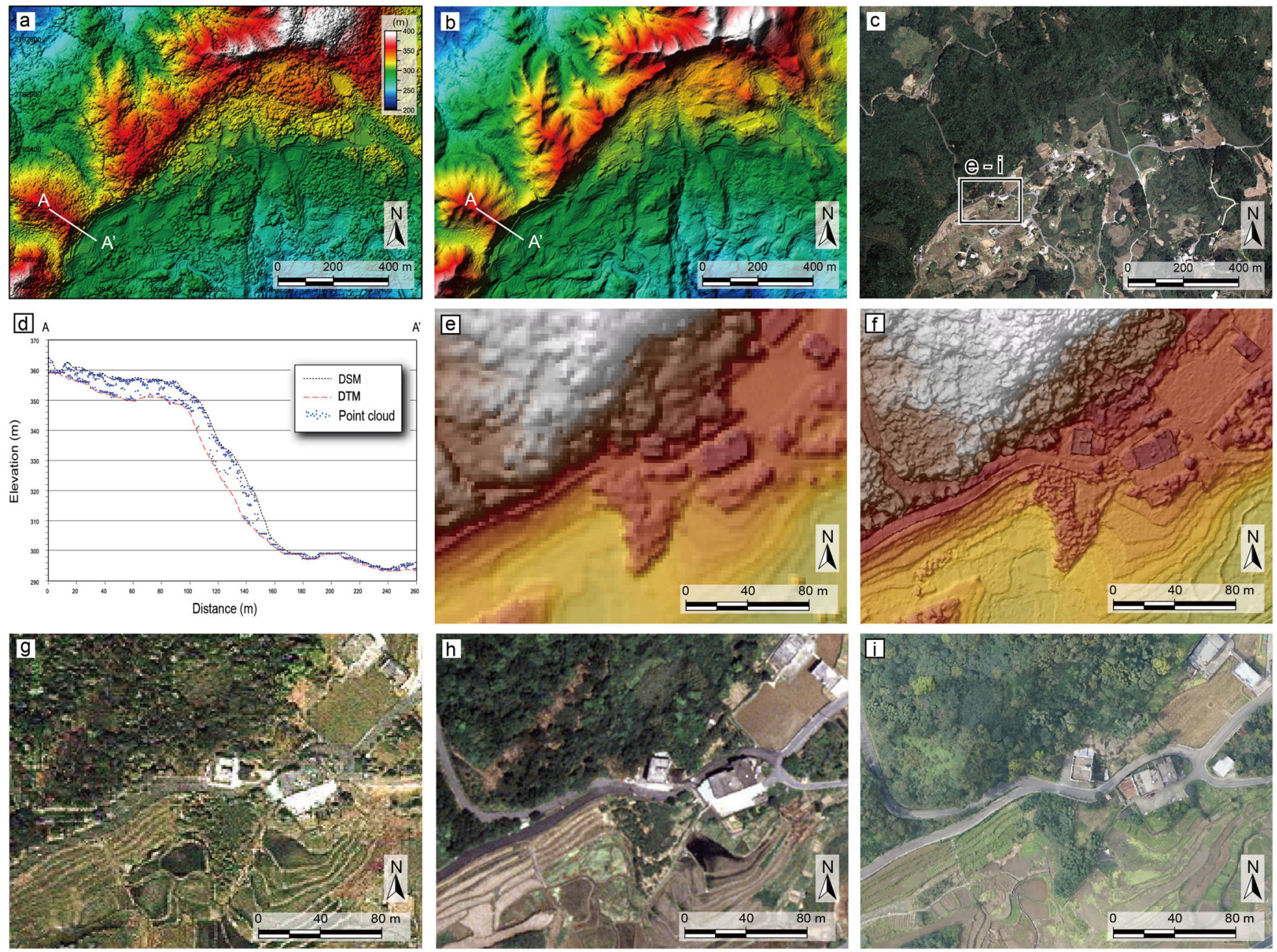

Figure 3. Comparison of images for the same area obtained from different sources. The area of the images is indicated in Fig. 2. (a) The $2 \mathrm{~m}$ resolution lidar digital surface model (DSM); (b) $2 \mathrm{~m}$ resolution lidar digital terrain model (DTM); (c) orthorectified aerial photograph captured in March 2003, $25 \mathrm{~cm}$ resolution; (d) the difference between the DTM and DSM represents the height of vegetation, whereas the DTM recorded the elevation of the bare ground surface, illustrated from lidar point clouds. The locations of the profile A-A' marks are indicated in Fig. 3a and b. (e) Enlargement of the $2 \mathrm{~m}$ resolution lidar DSM; (f) enlargement of the $8 \mathrm{~cm}$ resolution UAS DSM; (g) enlargement of the $1 \mathrm{~m}$ resolution IKONOS satellite image captured in November 2003; (h) enlargement of the orthorectified aerial photograph; and (i) enlargement of the orthomosaic UAS images. The enlargements are indicated in Fig. 3c.

tion. The ground appearances obtained from the IKONOS satellite image (Fig. $3 \mathrm{~g} ; 1 \mathrm{~m}$ resolution), aerial photographs (Fig. $3 \mathrm{~h} ; 25 \mathrm{~cm}$ resolution), and UAS images (Fig. $3 \mathrm{i} ; 8.5 \mathrm{~cm}$ resolution) show different levels of detail. Figure $3 \mathrm{~g}-\mathrm{i}$ show a dense forest covering the upper left corner of the images. Because of an annual rainfall of more than $2500 \mathrm{~mm}$ in this area, a vast portion of the study area is covered by vegetation. Dense vegetation often partially conceals morphological features in humid areas and has prevented detailed studies in the past on surface processes, e.g., incision or erosion.

Figure $3 \mathrm{a}$ and $\mathrm{b}$ show the DSMs and DTMs illustrating the differences in ground features with and without vegetation and buildings. The point clouds from which the DSM and DTM profiles were derived are shown and compared in
Fig. 3d. Figure 3c indicates human and agricultural activities in the crown area of the landslide, as shown in the lower halves of the images. Figure $3 \mathrm{c}-\mathrm{f}$ demonstrate the two landform regions with different vegetation coverage. The landform region with sparse vegetation corresponds and is almost equal to the region of landslide. The UAS DSM generated in this study is very similar to a so-called DTM, because the terrain is not concealed by the forest canopy. Thus, the geomorphologic analysis outside the landslide region depends mainly on the airborne lidar DSM and DTM in our study. Overall, the UAS and airborne lidar datasets can be mutually compensated for in the geomorphological analysis in this study. 


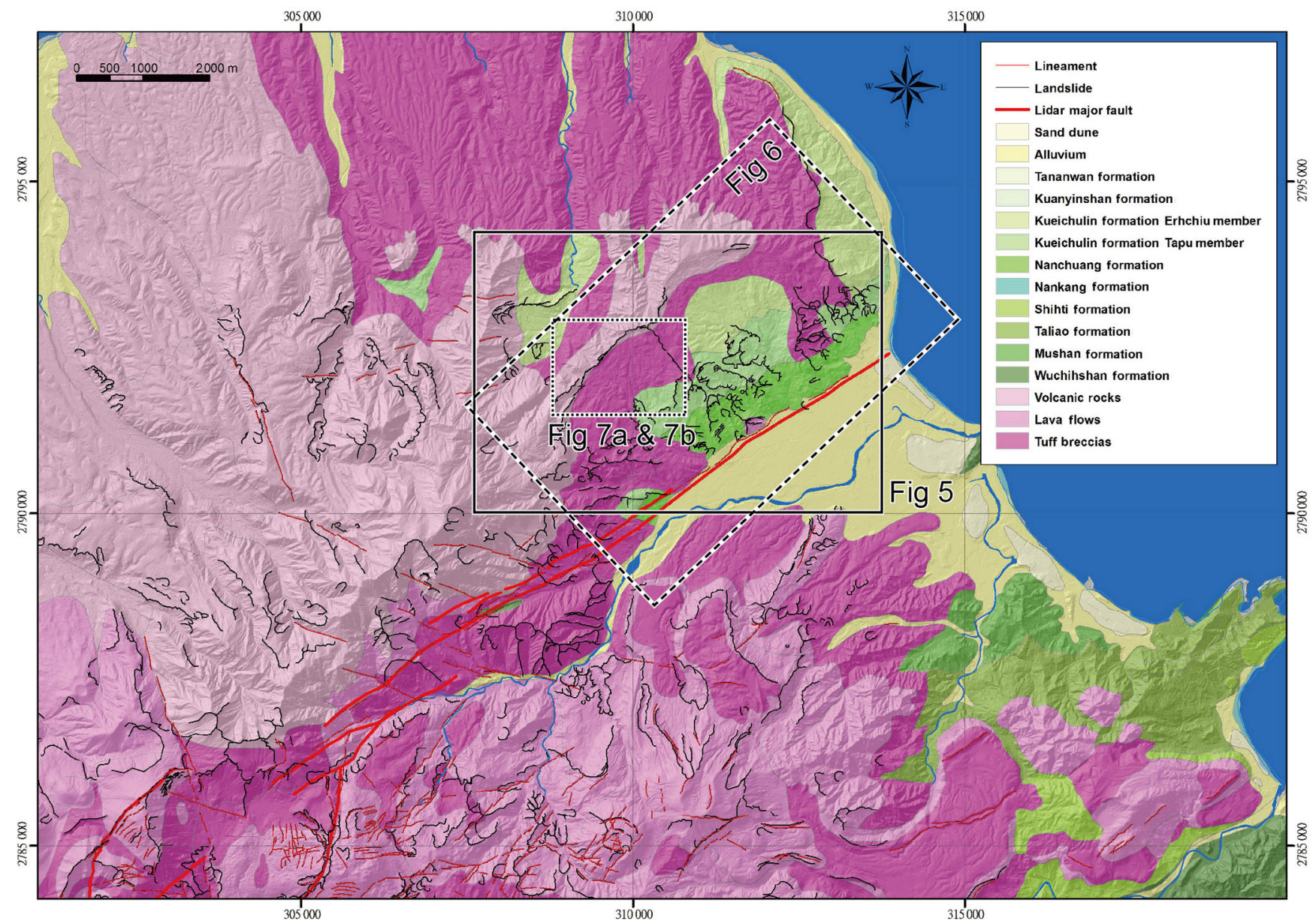

Figure 4. Regional geological map around the study area. Note that different components are illustrated, including faults, lineaments, and landslide scarps. In addition, many landslides are identified around the Tatun Volcano region. The study area was composed of sedimentary rock and superposed by volcanic rocks. Part of the volcanic rocks was eroded away, exposing the underlying Plio-Pleistocene sedimentary rock.

\section{Results of morphological analysis}

Morphological analysis is a key means of landslide identification. Satellite images or aerial photographs are traditionally used to perform morphological analysis. A DEM may provide more landform information and is typically developed by pairing satellite images or aerial photographs. However, the resolution of DEMs derived from either satellite images or aerial photographs is insufficient for performing highly detailed morphological analysis. For example, dense vegetation in humid areas often conceals part of the landslide's morphological features; this situation is readily resolved by using airborne lidar data and high-resolution UAS images. Lidar laser pulse emission can penetrate the barriers of different media (trees, clouds, and vegetation) based on corresponding reflections. UAS images and associated DSMs can produce datasets with decimeter to centimeter resolutions, which enable detailed photointerpretation and geological structure analysis. In this study, the DEM data ac- quired from the lidar images and UAS dataset were selected as the fundamental sources for detailed morphological analysis. Figure 3 demonstrates the differences in quality and in spatial resolution.

A detailed regional geologic map was reproduced by investigation from the high-resolution DEMs prior to the landslide study, as illustrated in Fig. 4. The geological structures, e.g., lineament, fault, fold, and especially the landslides, are interpreted directly from the lidar DTM and DSM, and UAS DSM and 3-D model, then validated in the field. The color patches represent strata boundaries initially from existing geologic maps, and they were then modified with lidar and UAS data (Yeh et al., 2014, 2017) and again validated in the field if possible. The components contain faults, lineaments and landslides shown by scarps (Fig. 4). For the first appearance, many landslides occurred in the study area and in the Tatun Volcano region. Based on several factors, e.g., size, distribution, classification, data accessibility, and especially on the 
UAS flight mission permission, the two largest landslides (XSL and CSL) were thus chosen as the target for this study.

\subsection{Geomorphological characteristics}

The geomorphological characteristics of a landslide can be divided into the depletion and accumulation areas. Most accumulation areas are prone to erosion by subsequent surface processes because of fractured and fragmented weak debris. Contrastingly, depletion areas composed of more competent bedrock tend to remain stable and are readily detectable. Therefore, the morphological analysis in this study focuses on the depleted areas shown in the UAS and lidar data. Despite some small landslides in the study area being identified from satellite images or aerial photograph analysis, limited resolution and dense vegetation obscured their detailed geomorphic characteristics. The small scarps and depletion depths indicate that they are shallow landslides. Figure 5 illustrates some of these landslides; among them, two largescale landslides, the XSL and the CSL, were selected for study.

The two main landslides have preserved some common morphological features. In contrast to the XSL, the CSL has preserved relatively more of the original topographic features characteristic of a landslide, including the circular crown, main scarp, and transverse ridge, particularly in its southwestern flank. Figure 6 shows the hillshade elevation view of the XSL and CSL. The CSL has many small, elongated bumps, known as transverse ridges, that indicate where displaced blocks used to rest, as well as the locations of induced ground deformation. The CSL has two remarkable shutter ridges with typical triangular facets (Fig. 6). Figure 7 explicitly illustrates the typical landslide landforms, e.g., main scarp and shutter ridges, from different perspective views. This phenomenon reveals that the sliding process has cut off two linear cliff remnants and generated these two triangular facets.

Furthermore, in Fig. 7b two linear extensional cracks right behind the main scarp represent the landslide retrogressive enlargement. The lineaments parallel to the triangular facet support the argument of landslide process, especially illustrated in Fig. 7i and j. The identifications of lineament are interpreted from the lidar DTM, and the UAS DSM is used to support that the terrain is not affected by other artifacts, simply from much higher resolution 3-D terrain data. The resolution of decimetric 3-D terrain model illustrated as in Fig. $7 \mathrm{~g}$ and $\mathrm{h}$ providing supplemental ground truth.

The morphological features of landslides may disappear during subsequent surface processes, most likely because of progressive landslide, surface erosion, normal faulting, and fluvial development. Consequent erosion by heavy precipitation induced by the annual northeast monsoon markedly modifies the accumulation areas of landslides, rendering them unable to retain their original topography. Moreover, the erosion may be further enhanced by normal faults cut- ting the toe of the slope. The trace of the JSF (also known as the $\mathrm{SCF}$ ) is located on the southeastern side of the landslide and is shown in Fig. 5. These major factors have resulted in stream initiation and the development of drainage systems. In the depletion zones of both XSL and CSL, two gullies, marked as Xishi Creek and Chinshui Creek in Fig. 6, developed on a gently dipping slope at an angle of $6-7^{\circ}$. On the XSL, the drainage basin of Xishi Creek showed a symmetric dendritic pattern in the slide area. However, on the CSL, the drainage pattern was not dendritic but rather a curved parallel system, suggesting subsequent morphological processes.

As mentioned and illustrated in Figs. 5 and 6, the CSL is marked with circular crown, main scarp, circular concentric transverse ridges in the rear of the main body, whereas most of the landslide morphologic components in the XSL have been modified by human activities, e.g., the graveyard illustrated in Figs. 3b, c, and 6. For example, the crown area of the landslide has been developed into a graveyard with clearly preserved lateral flanks (Figs. 6 and 7). According to the criteria of landslide classification proposed by Varnes (1978), the two major landslides, from the currently observed landslide geomorphologic components, suggest that the landslides are best classified as rotational or translation slides.

\subsection{Estimation of the landslide dimensions}

This study considered the nature of a volcanic dome for reconstructing its morphology before a landslide. The undisturbed shape of the volcanic edifice, particularly for a stratovolcano with one main eruption center, typically mimics a conical dome. Subsequent large-scale landslide events generate morphological depressions and change the original topography. To reconstruct the paleolandform, a large depleted area may be estimated by refilling the depletion. For example, for the case shown in the inset of Fig. 8, despite the radial shallow erosion gully, two-thirds of the northwestern flank remained conical in shape. Thus, the geometry of the northwestern flank was used to model the undisturbed conical shape of the volcano. The depleted area was manually filled by inserting several linearly aligned points within the slide area. The linearly aligned points in Fig. 9a show the undisturbed topography before a landslide. A local high envelope surface was subsequently calculated with a search circle. Because the calculated envelope surfaces may not cover all areas, the search circle was then moved gradually around the grids to assign new heights. The procedure of determining the local high envelope surface and assigning new heights to the grids is iterative until the results are converged.

Figure 8 shows the differences between the real and reconstructed DTMs, as shown by several profiles from the Tatun volcano group. The locations of the profile lines were selected according to the landslide area. The trend of the profile lines was selected from around the volcano summit to the toe of the slope. For every profile, the point locations were selected from the highest local envelope surface to avoid as 


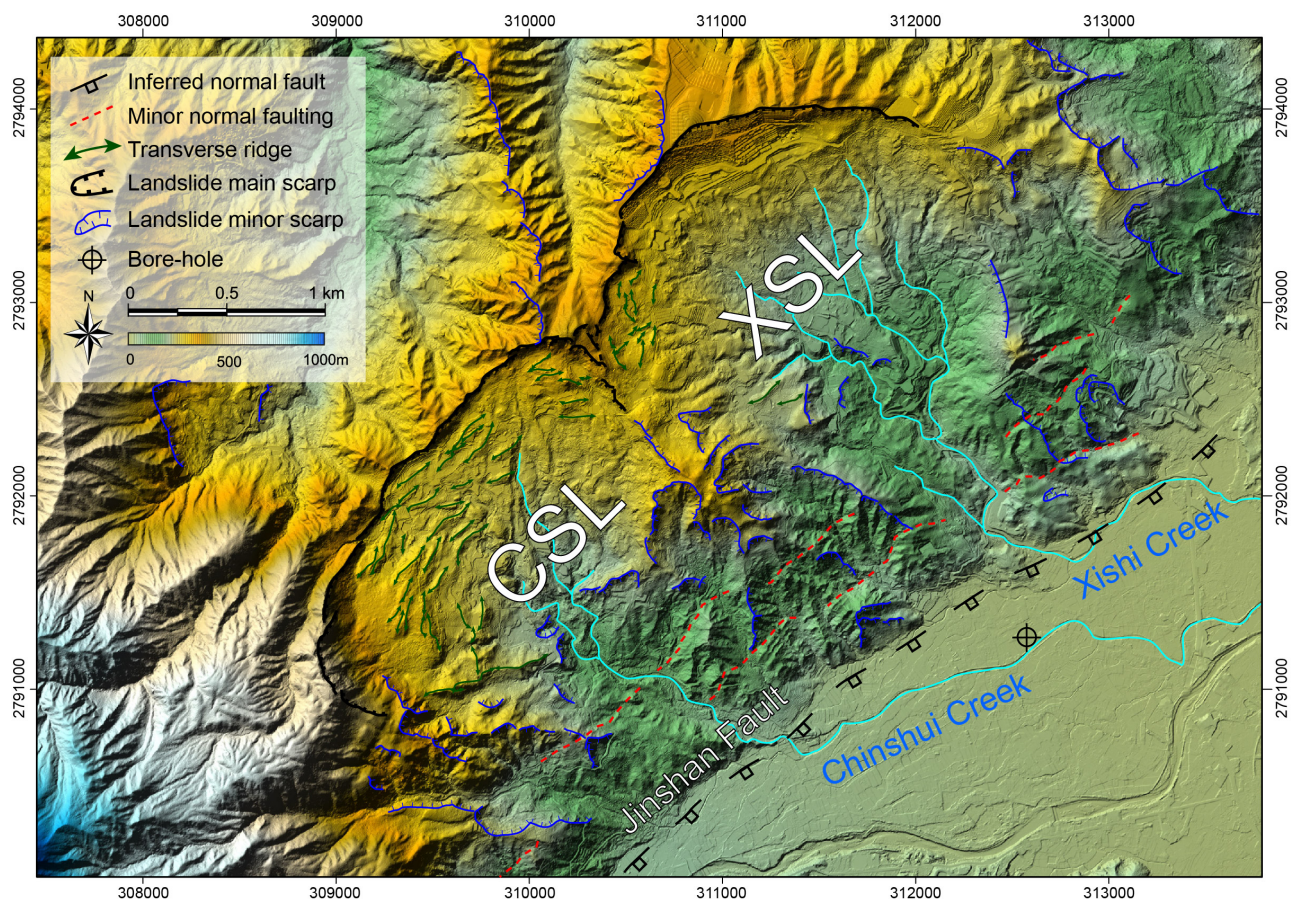

Figure 5. Hillshade map of the study area obtained from the lidar DTM. The morphological features in the depleted zone have been preserved, namely the main scarp, minor scarp, and transverse ridges. Notably, several small landslides are located on the volcano flank within the two main landslides. The region and the location of this figure are indicated in Fig. 4.

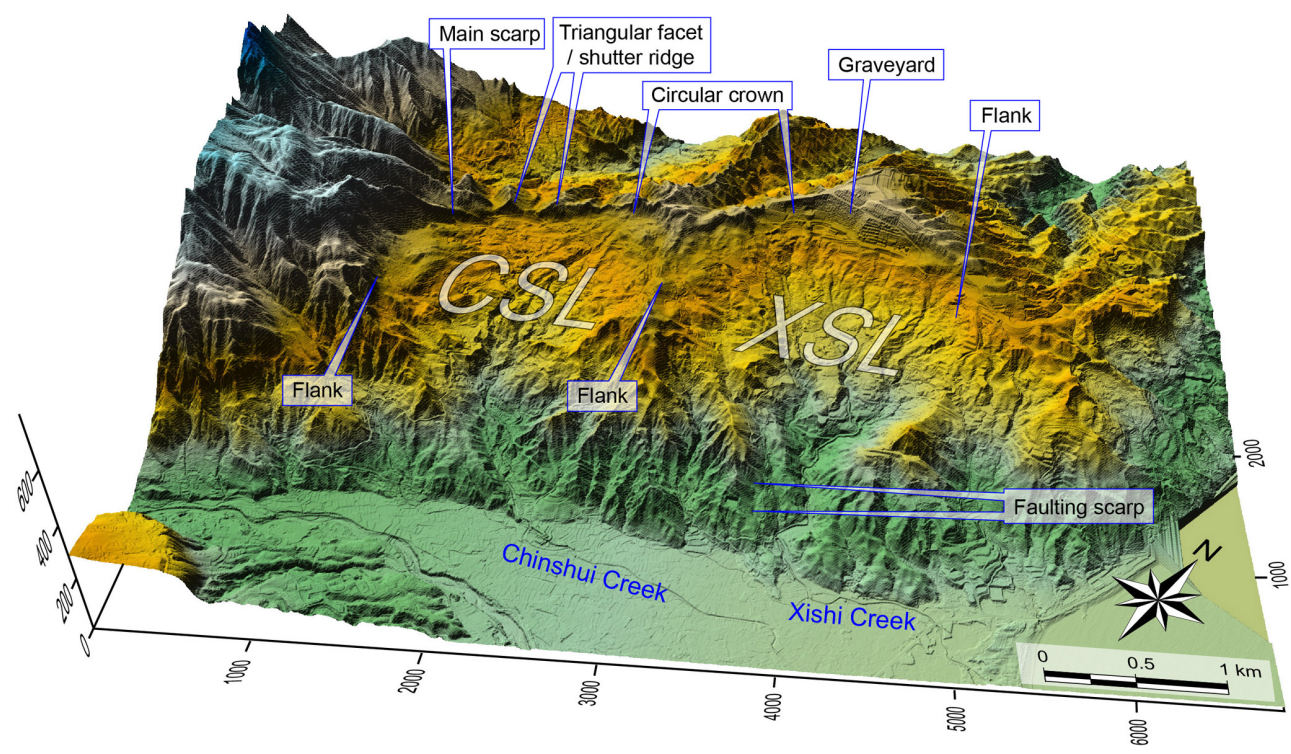

Figure 6. Perspective view of the 3-D hillshade map of the study area from the lidar DTM. The morphological features, namely circular crowns, flanks, main scarps, shutter ridges, and triangular facets, can be observed. However, part of the main scarp in the XSL was significantly modified as a graveyard (Fig. 3b and c). Only part of the depletion zone was preserved on the two main landslides. In the CSL, clearer topographic features of the sliding process were preserved, possibly indicating that the CSL is newer than the XSL. The location of this figure is indicated in Fig. 4. 

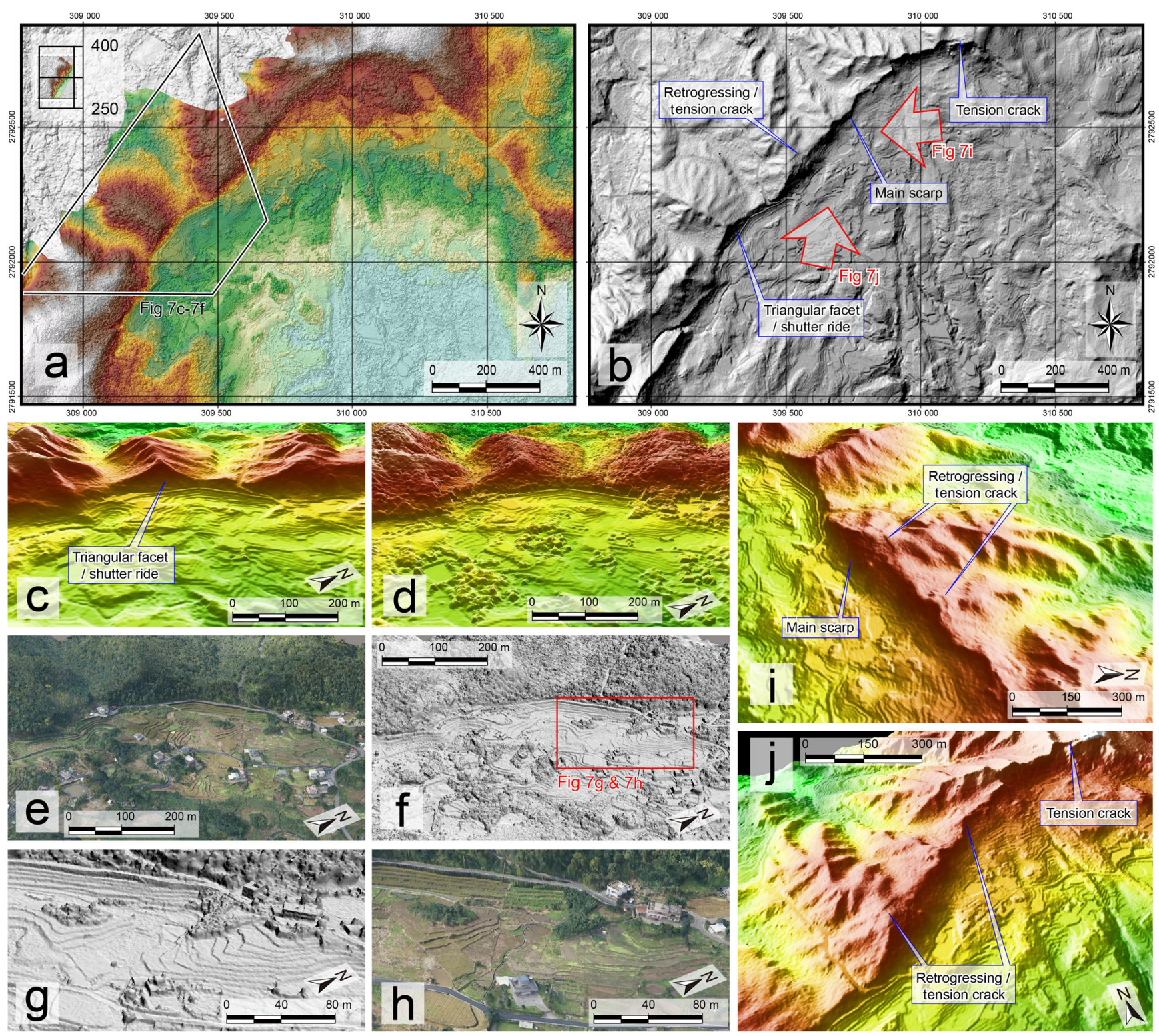

Figure 7. Comparison of topographic datasets for the same area acquired from different sources, including airborne lidar DSM, DTM, and UAS DSM. (a) UAS DSM data at $8.5 \mathrm{~cm}$ resolution around the crown area of CSL; (b) hillshade image from $2 \mathrm{~m}$ resolution lidar DTM, where (a) and (b) denote the same region and are indicated in Fig. 4; (c) magnified side view around the main scarp area from the lidar DTM; (d) magnified side view from lidar DSM; (e) UAS 3-D model magnified side view with optical images; (f) UAS 3-D model magnified hillshade side view, where (c), (d), (e), and (f) share the same perspective, indicated in (a); (g, h) enlargement of the UAS 3-D model, indicated in (f); (i) color hillshade side view around main scarp; (j) another perspective view around main scarp. The direction of perspective view direction is indicated in (b). Both (i) and (j) are illustrated from the lidar DTM. The morphological features, e.g., main scarp, shutter ridge, and triangular facet, are clearly observed. Note that retrogressive tension cracks were identified above the main scarp.

many points of surficial erosion as possible. The profiles before and after reconstruction were fitted by exponential and power-law functions, as shown in Table 1. The correlation coefficient values $(R)$ for the profiles throughout the sliding area were calculated. High $R$ values indicate better fit to the filled DTM profile, thus correlating with the ideal conical volcano shape. The $R$ values of the reconstructed DTMs for the landslides were considerably similar to those of profiles where no landslides occurred, as indicated by the profiles P1-P3 in Fig. 8. Thus, these reconstructed DTMs for the landslides were reasonably restored to their prelandslide morphologies.

Figure 10 shows the estimated isopach map of the cut-andfill depth for the two main landslides. The landslide volume 
Table 1. Correlations of several profiles from the DTM data and curve-fit results.

\begin{tabular}{|c|c|c|c|c|}
\hline \multirow[b]{2}{*}{ Profile } & \multicolumn{2}{|c|}{ Type of curve to be fitted } & \multicolumn{2}{|c|}{ Corresponding $R^{2}$} \\
\hline & Exponential & Power & $\begin{array}{r}R^{2} \\
(\exp )\end{array}$ & $\begin{array}{l}R^{2} \\
(p)\end{array}$ \\
\hline P1 & $1006.2 \times \operatorname{Exp}(-0.0003 x)$ & $1 \times 10^{6} x^{-1.0398}$ & 0.9876 & 0.9412 \\
\hline $\mathrm{P} 2$ & $1020.2 \times \operatorname{Exp}(-0.0002 x)$ & $14695 x^{-0.4204}$ & 0.9554 & 0.9808 \\
\hline P3 & $1075.9 \times \operatorname{Exp}(-0.0003 x)$ & $16859 x^{-0.4502}$ & 0.9743 & 0.9482 \\
\hline P4 & $830.9 \times \operatorname{Exp}(-0.0002 x)$ & $25236 x^{-0.5054}$ & 0.7843 & 0.8642 \\
\hline $\mathrm{P} 4^{*}$ & $908.5 \times \operatorname{Exp}(-0.0002 x)$ & $15855 x^{-0.433}$ & 0.9148 & 0.9914 \\
\hline P5 & $484.3 \times \operatorname{Exp}(-9 E-5 x)$ & $1133 x^{-0.146}$ & 0.4923 & 0.4167 \\
\hline $\mathrm{P}^{*}$ & $599.5 \times \operatorname{Exp}(-0.0001 x)$ & $2919 x^{-0.2484}$ & 0.8959 & 0.7297 \\
\hline P6 & $384.7 \times \operatorname{Exp}(-1 E-4 x)$ & $776 x^{-0.1321}$ & 0.3681 & 0.2944 \\
\hline $\mathrm{P}^{*}$ & $526.3 \times \operatorname{Exp}(-0.0001 x)$ & $1973 x^{-0.2109}$ & 0.8912 & 0.8307 \\
\hline
\end{tabular}

Profiles after reconstruction; $R^{2}$ : coefficient of determination; DTM data are fit pursuant to both exponential and power laws. The locations of the profiles are shown in the upper right corner; $\mathrm{P} 1, \mathrm{P} 2$, and $\mathrm{P} 3$ did not cross the sliding area, whereas P4, P5, and P6 crossed the sliding area. To illustrate the different effects of erosion, the original and reconstructed (marked with *) profiles are shown for comparison purposes. Because P7 (marked in Fig. 8) does not trend in the direction of the volcano slope, it was not included in the calculation.

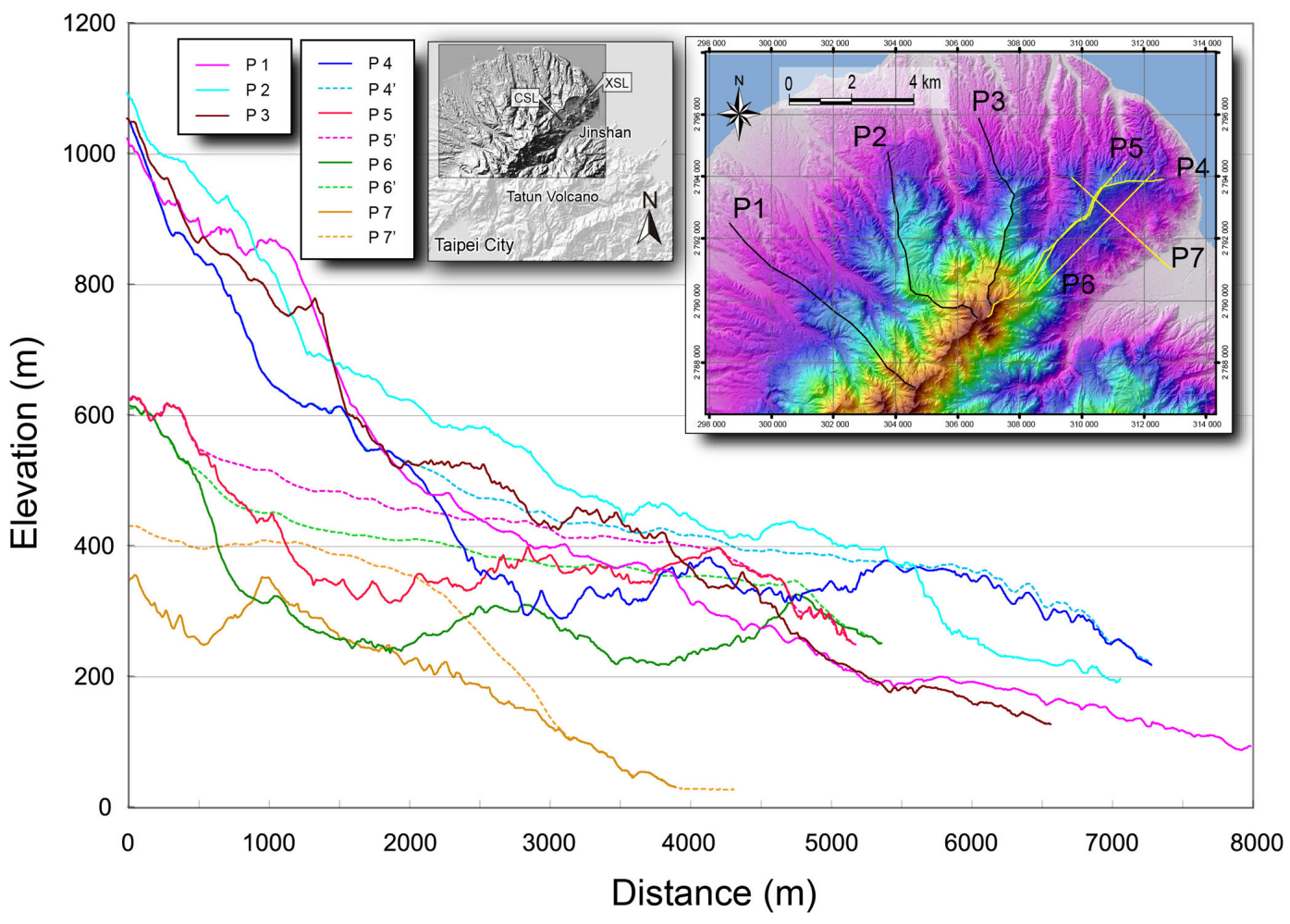

Figure 8. Topographic profiles of the Tatun volcanic cone. For P4, P5, and P6, profiles from the original (solid line) and the reconstructed (dashed line) DTMs are shown. The profile locations are shown in the inset in the upper right corner. The original ground surface is extracted from the lidar DTM.

was calculated from elevation changes before and after each landslide. The cut-and-fill depth was estimated based on the elevation differences between the current and reconstructed DTMs. The cut-and-fill volume is based only on the difference of DTM and did not account for some of the remaining debris on the slip surface. On the other hand, the volume does not consider how many landslide events have occurred to induce such volume due to insufficient evidence. The estimation of landslide volume indicates the minimum volume in this study. Finally, the total cut volume of the CSL and XSL was calculated to be at least $820 \pm 20 \times 10^{6} \mathrm{~m}^{3}$, covering an area of approximately $7 \mathrm{~km}^{2}$; this volume is approximately 6 

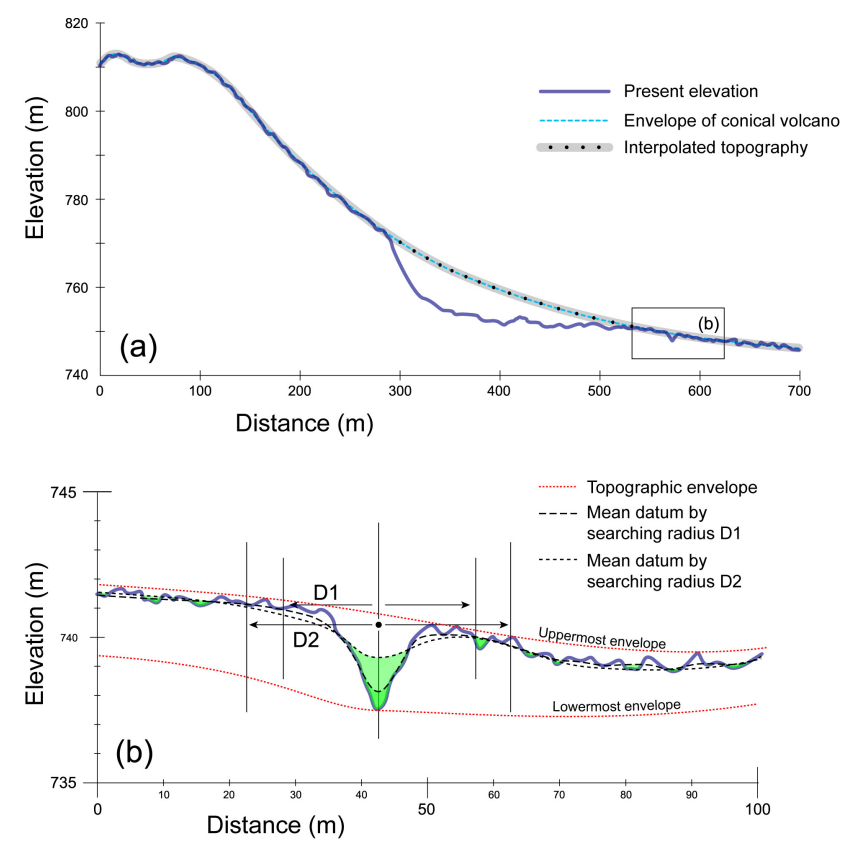

Figure 9. Schematic illustration showing how the envelope of paleomorphology was obtained from the current DTM morphology. (a) The configurations of the undisturbed volcanic dome and current profile. The undisturbed volcanic dome facilitates the selection of manual interpolation points that better fit the volcanic edifice. (b) The configuration of the possible mean paleodatum correspondent to the other two enveloping surfaces. The shaded area represents the river incision. D1 and D2 correspond to different radii for topographic regression and restoration. The idealized profile was simplified and modified from a part of topographic profile P4.

times larger than that of the largest landslide ever reported in Taiwan (Chen et al., 2005, 2006).

\subsection{Morphological reconstruction and evolution in sliding area}

The evolution of slope degradation is the most prominent type of morphological change but may not be sufficiently rapid in showing changes. The fluvial incision process may record the efficiency of the slope evolution (Chen et al., 2006). Fluvial development is invariably accompanied by riverbed incision. The gullies develop into surface runoff flow along small ditches on the bare ground; the incision of the ground surface by these ditches is determined accordingly. Therefore, to eliminate the small-scale surficial disturbances after landslides, gullies should be filled to reconstruct the original topography, as shown in Fig. 9b. The mean level of the original ground surface and the average datum drawn from an enveloping surface were used to accurately fill the gullies. To obtain the trend of the topographic surface, the current DTM grid data were processed and weighted by a Gaussian function over a small area, defined by a search radius (D1 and D2, Fig. 9b). The different radii in the search

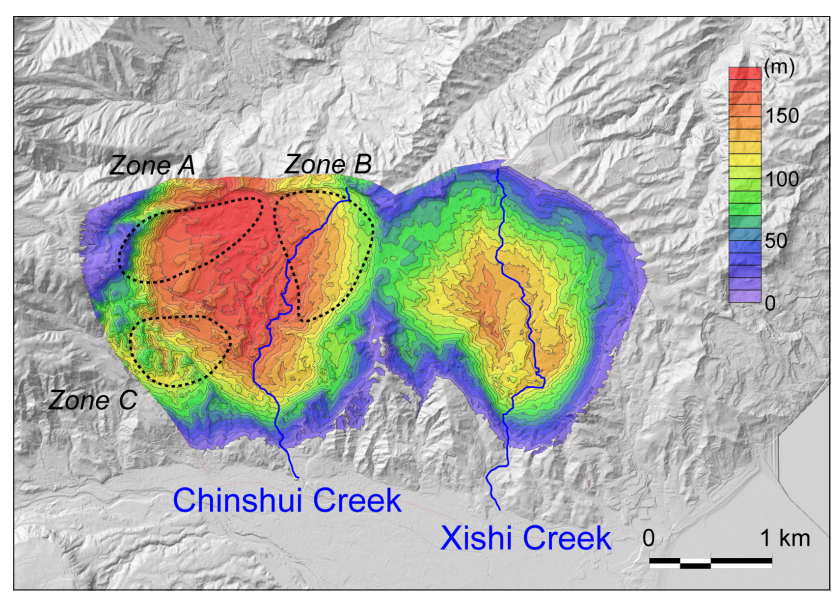

Figure 10. Isopach map of the landslides. The depleted landslide mass is calculated from the difference in height between the current and reconstructed topographies. The contour bands are shown at $10 \mathrm{~m}$ intervals. The original ground surface is extracted from the lidar DTM.

circle represent different thresholds for river development and surface roundness. Within the search circle, the means of the grid data were assigned to the corresponding value applicable to the center of the circle. The search circle was then scanned over the grids. By using this method, the local unevenness induced by small gully incisions can be smoothed.

The differences between the current DTM and its enveloping surfaces can serve as an index for small-scale landslides (e.g., surficial erosion or shallow landslides). Therefore, the average datum should be in neither the uppermost nor the lowermost enveloping surface but instead be at the intermediate level, as shown in Fig. 9b. On identifying the average datum, the subsequent river incision was revealed by the shaded area, as shown in Fig. 9b. Unlike the part of the ground where gullies developed, the other portion of the landslide retained its original surficial roughness. The current relief above the averaged datum was not modified because it was deemed that the unevenness or roughness of the original topography had not been affected by the surface process, e.g. erosion. Therefore, when the calculated mean elevation exceeds the elevation of the circle center, the center elevation is assigned as the mean elevation. The reconstructed morphology is the thick line shown in Fig. 9b, and the shaded area, which is the difference between the old and current DTM, reveals the possible areas of river incision. The hatched areas indicated the eroded volume that formed the current gully (Fig. 9b) under no pronounced morphological changes, such as a large-scale landslide. This method could effectively restore the disturbances induced by small gullies or riverbed incision. Furthermore, the different search radii may render different envelopes. The variations in the envelopes obtained from different search radii inherently reflected the range of possible errors in determining the incision depth (Fig. 9b). 


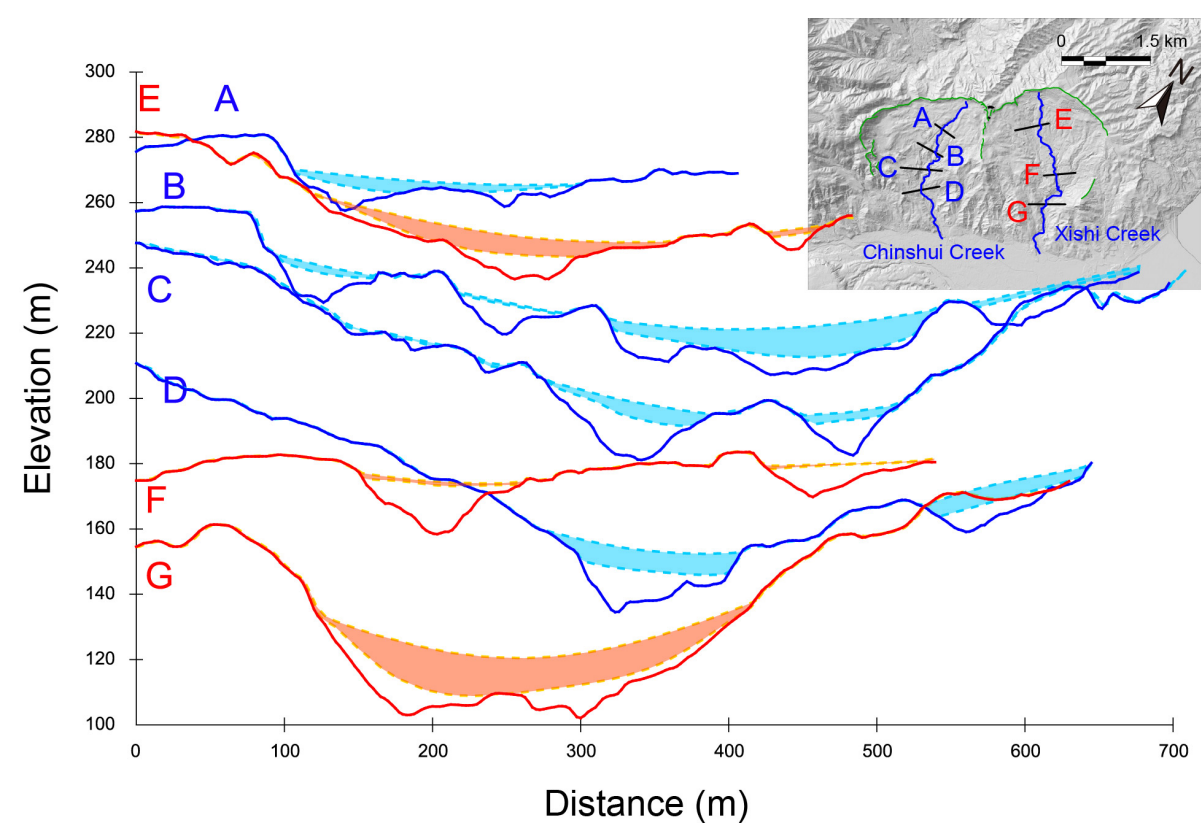

Figure 11. Cross sections of the river valleys situated in the landslide area. The shaded area indicates the possible datum ranges obtained within various search radii (D1 and D2 in Fig. 9b). If the current elevation is lower than the possible paleodatum, this depth represents the amount of the incision. The upper and lower bounds are indicated by the semiopaque dashed line. The locations of the cross sections in the landslide area are shown in the inset. The original ground surface is extracted from the lidar DTM.

Figure 11 demonstrates the upper and lower bounds of several cross sections along the two creeks located within the slide area. The discrepancies between various reconstructed DTMs result from the different thresholds (search radii) used during reconstruction.

Figure 12 shows the longitudinal profiles of the two creeks located on the XSL and CSL (Fig. 10). The inclined solid lines in Fig. 12 represent the current elevations along the two creeks; the dashed lines indicate the upper and lower bounds of the enveloping surface obtained by different search radii D1 and D2, as indicated in Fig. 9b. The horizontal distances were individually normalized by the analyzed river segments from upstream Chinshui Creek to downstream Xishi Creek. The analyzed segments of the river profile were completely contained within the landslide areas, from the main scarp to the junction of the pediment and the delta fan. The elevation differences between the current DTMs and envelope surface were calculated (shaded bands, Fig. 12). Moreover, the elevation differences between the upper and lower bounds denote the range of error in estimating riverbed incision.

A mean level curve represents the main trend of the incision depth distribution. If the raw data of the mean depths are used, the derived curve would appear jagged. Therefore, to obtain a smooth mean value curve, the following procedures were developed.

1. The mean incision depth should be located between the upper and lower bounds along the creeks, as calculated using the search radii D2 and D1, respectively.
2. Three gully erosion depth-versus-distance curves - the maximum, minimum, and mobile averages - are calculated from the mean of the maximum and minimum enveloping surfaces. At each location along the creek, the mean depth of the mobile average curve located with a horizontal span of approximately $400 \mathrm{~m}$ is calculated. The derived mean depth is then assigned as the representative mean depth at this location.

Using these procedures, a smooth mean incision depth versus the horizontal distance curve can be obtained, as shown by the bold solid lines in Fig. 12. This curve represents the possible distribution of incision depth along the creek. The results revealed a maximum valley depth of approximately $15 \mathrm{~m}$, which was notably situated between the middle and lower parts of the hill slope. This phenomenon differs from common river profiles, where the deepest depth of the valley is often located near the upstream rather than the downstream portion.

\section{Discussion}

\subsection{Landslide generation}

Several processes can weaken the volcanic edifice, particularly hydrothermal activities (de Vries et al., 2000; Reid et al., 2001; Reid, 2004; Norini and Lagmay, 2005), which result in high pore pressures and enhance the alteration process, thus converting strong rocks into clays. Catastrophic 


\section{3-D river profile and evolution}

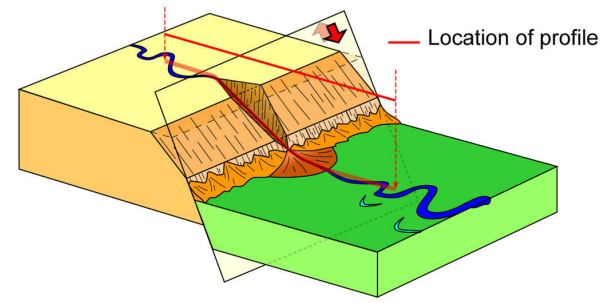

2-D conceptual model

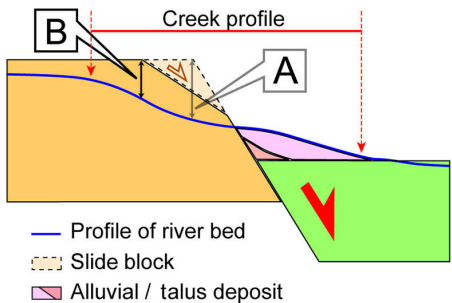

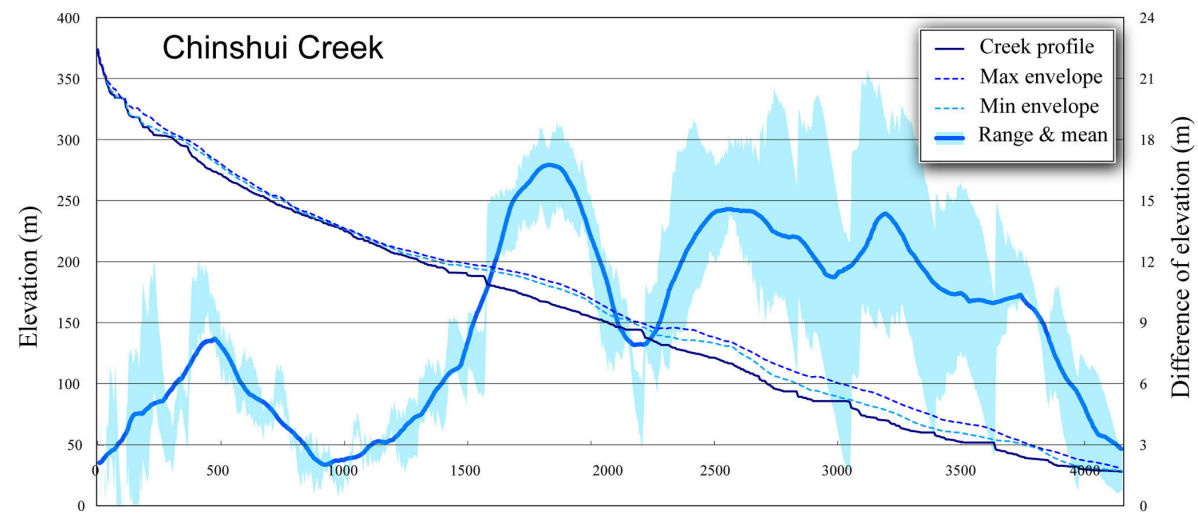

Distance of creek profile from upstream to downstream (m)

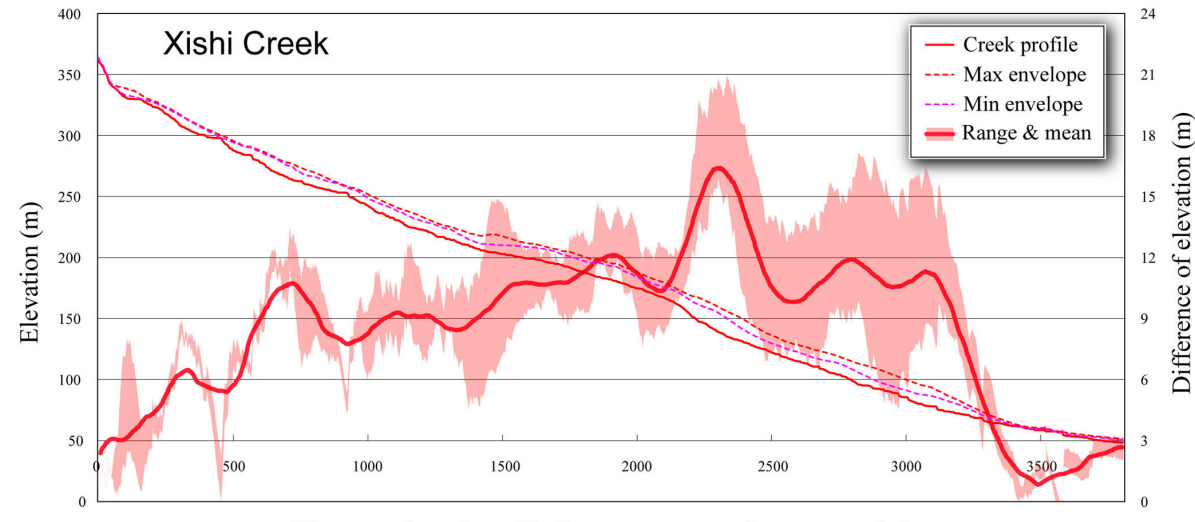

Distance of creek profile from upstream to downstream (m)

Figure 12. River longitudinal profile and morphological evolution in the sliding area. Because of normal faulting, the substantial subsidence of the hanging wall led to a sudden reduction of the river bed. The block diagram shows the relationship between the river profile and normal faulting. The sharp fault scarp can be smoothed or even eroded by many small-scale landslides along the fault line. Therefore, the largest section of river incision may be located far from the fault scarp (marked as B), rather than close to the fault scarp (marked as A). The incision of creeks is obtained from the difference between the current and reconstructed profiles. The locations of the creek segments are shown in Fig. 11. The profile length has been normalized using the differences in the total length between the water source and basin mouth. The shaded bands form the error bar derived using different methods. The terrain elevation is extracted from the lidar DTM.

collapses occur when a volcano becomes structurally unable to support its own load. These processes generate radial and concentric instabilities in the case of no other structural anisotropy. Typically, these landslides propagate outward from the volcanic cone and extend downslope. However, the XSL and CSL slid perpendicular to the conical shape of the volcanic slope, thus prompting us to discuss several specific points.

In a normal situation, landslides frequently have a circular crown and main scarp. However, Fig. 10 shows an ir- regular scarp, and the estimated distribution of the sliding depth of the CSL showed an irregular form, marked as zone $\mathrm{C}$ in Fig. 10. Zone $\mathrm{C}$ implies a secondary slide with a circular crown after the main sliding event. Moreover, because zone A maintains a less disturbed original landslide morphology than does zone B, zone A could be the more recent of the two events (Fig. 10). Meanwhile, the twist of a parallel drainage pattern (Figs. 5 and 6) and a concentric river developed within the slide area (Fig. 10) suggested that the initial slide mass experienced subsequent movement. These obser- 
vations suggest more than one sliding event. Thus, the CSL is a combination of one main landslide and more than two subsequent small landslides within it. However, from the geomorphologic features denoted in Fig. 10 (zones A, B, and $\mathrm{C})$, the regions show different degrees of preservation of the landslide geomorphologic components. The CSL can be interpreted to have occurred from a combination of multiple landslide events. In addition, the CSL and XSL preserved different degrees of landslide geomorphologic components, and the creeks as illustrated in Figs. 5, 6, and 11 developed within the depletion zone with different drainage patterns and varying incision depths. These observations suggest that more than one sliding event has occurred in the study area.

Finally, a comparison of the XSL and CSL revealed that typical landslide morphological features are more well preserved in the CSL, indicating that it is newer than the XSL, assuming that the weathering rate for both landslides is similar. A large landslide volume coincides with a large accumulation area near the toe. However, as shown in Figs. 5, 6, and 11, a flat alluvial plain was observed instead of an accumulation of colluvial or talus deposits. Normal faulting along the JSF, also known as the SCF, particularly where the trace of the JSF was reactivated as a normal fault, ultimately yielded a half-graben near the toe area and thus accommodated the volume. This process may plausibly account for the missing colluvial deposits, as illustrated in Figs. 5 and 6. An additional line of evidence supporting this explanation is that the river incision profiles had maximum erosion areas located from the middle to lower slope and were abruptly truncated near the toe area (Fig. 12, inset). This particular landform indicates the subsiding process along the fault trace, consuming the deposited debris that would otherwise be present at the slope toe. The remaining displaced material in the CSL suggests a combination of multiple landslide events. However, most of the displaced material in the XSL has been eroded away and it is not possible to estimate how many events are involved in the XSL. On the other hand, the two linear extensional cracks right behind and parallel to the main scarp represent the landslide retrogressive enlargement (Fig. 7b, i and $\mathrm{j}$ ). These phenomena denote the active and progressive evolution of the CSL.

To conclude the landslide generation, the normal faulting in the region started from $400 \mathrm{ka}$ and is activated continuously ever since. The faulting was identified in the Taipei Basin area and northeastern offshore Taiwan, with the fault line situated on both sides of the study area (Figs. 4 and 5). In addition, the fault line was recently identified and linked together as only one normal fault in Tatun Volcano region. In conclusion, for the relative age of the landslide, we interpret that the landslide has been triggered since right after normal faulting started and the formation of Tatun Volcano, which is far later than $200 \mathrm{ka}$. Regarding to the different generation of landslide, the geomorphologic components also show different degrees of preservation within the two observed land- slides. Furthermore, the CSL is interpreted to have occurred from a combination of multiple landslide events.

\subsection{Landslide slip surface and volume estimation}

According to geological data and field observations, the Tatun volcanic rocks overlie the Mio-Pliocene sedimentary rocks (Figs. 1 and 4). Because of the clear contrast in the rock strength and strata unconformity, the contact surface of the two rock types may easily serve as the rupture site for the sliding surface, thus indicating that most landslide debris was eroded or slid away when the contact surface was largely exposed. Thus, although the estimated volume was considered the minimum landslide volume, volume estimation should approximate the actual volume in this special case.

Regarding the landslide volume, the position and morphology of the slip surface indeed will affect the calculated cutand-fill volume. In this study the slip surface is difficult to observe in the field due to soil cover and has not been definitely identified. Nevertheless, the sedimentary rock basement and the volcanic rock cover have been well mapped both on the geologic map and in field survey in the region (Figs. 1 and 4). Based on the distribution of rock types, it is supposed that the contact between the volcanic cover and the underneath sedimentary rocks may serve as a weak plane for the slip surface. On the other hand, the calculated landslide volume is derived from the difference of DTM, which denotes only the minimum volume and does not take into account the remaining debris still resting on the supposed slip surface, especially for the larger landslide CSL, as shown in Fig. 10.

For the XSL, the maximum cut depth was approximately $150 \mathrm{~m}$. The maximum cut area was situated in the central zone of the sliding area and showed a symmetrical reverseconic shape; a uniform erosion process in the accumulated area may account for this pattern. For the CSL, the sliding mass had a sliding depth of approximately $200 \mathrm{~m}$ and a wide and flat bottom. The volume of the CSL landslide was approximately 3 times larger than that of the XSL. It is noted that there are two small creeks, the Xishi and the Chinshui, and several incised gullies on the ground surface (Figs. 6, 7, and 10). Figure 12 shows that the average incision depth ranges from a few to some $15 \mathrm{~m}$, but this is limited closed to the creeks and gullies. Comparing with the overall landslide region of $7 \mathrm{~km}^{2}$ and over $100 \mathrm{~m}$ in depth, the effect of gully incision affecting the landslide volume estimation may be neglected. Nevertheless, these surface processes may affect and accelerate the landform modification within landslide area and play a key role in the geomorphologic evolution.

Although the assumed ideal volcanic conical dome may deviate from the true shape of the topography, the estimated results provided useful information about ideal magnitudes of the scale and volumes of landslides, which are several times higher than the magnitudes previously reported in Taiwan. 


\subsection{Landslide evolution}

Surface deformation (e.g., normal faulting) may enhance and accelerate surface processes (Densmore, 1997; Strecker and Marret, 1999; Ambrosi and Crosta, 2006; Bucci et al., 2013, 2016; Scheingross et al., 2013). The study area morphology revealed that these processes extended from the deformation zone toward other parts of the landscape. The evolution of the riverbed profile over a short timescale clearly demonstrated such processes. As shown in Fig. 12, the substantial subsidence of the hanging wall led to a sudden decrease in riverbed elevation at the boundary of the footwall and hanging wall, particularly on the footwall side. The subsiding normal fault enabled faster incision on the footwall at the section where the river intersected the fault. Meanwhile, the sharp fault scarp could be smoothed rapidly or even destroyed by many small-scale landslides along the footwall side of the fault trace. In brief, the largest amount of river incision was not necessarily at the location nearest to the fault scarp (marked as A in Fig. 12) but was located at a certain distance from the fault scarp (marked as B in Fig. 12). The observed maximum incision depth was approximately $15 \mathrm{~m}$, implying that the actual maximum incision could be several times greater. Because washing out the colluvium and producing an incision require considerable time, the incision of tens of meters implies that the erosion processes continued long after the main landslide occurred.

In northern Taiwan, the tectonic activity of the region is in extensional regime. The Shaochiao normal faulting contributed to the formation of Taipei Basin by over $1000 \mathrm{~m}$ throw of the fault separation. The normal faulting has been very well documented recently, and a very active faulting behavior has been drawn as a conclusion (Teng et al., 2001; Shyu et al., 2005; Chen et al., 2007, 2010; Huang et al., 2007; Chen et al., 2010). The results showed the normal faulting slip rates between 8.2 and $1.8 \mathrm{~mm} \mathrm{yr}^{-1}$. This normal faulting not only resulted in the formation of the Taipei Basin but was also probably related to the continuous eruption of the Tatun Volcano (Teng et al., 2001). The faulting that was identified in the Taipei Basin situated on southwestern side of the study area. The faulting in northern offshore Taiwan has also been investigated and identified to be active normal faulting (Hsiao, 1997; Hsiao et al., 1998). Recently, these faulting observations were interpreted to be linked together as only one normal fault in Tatun Volcano region across the study area. The total length of the newly observed Jinshan normal fault is more than $130 \mathrm{~km}$, much longer than previous thought.

The systematic historical record of the study area dates back to the 18th century. Two major geological hazards have been documented: seismogenic normal faulting responsible for the formation of Kangshi Taipei Lake in 1694 (Yu, 1959; Tsai, 1985; Shieh, 2000) and the Jinshan Tsunami triggered by the Keelung earthquake in 1867 (Tsai, 1985). However, the Jinshan landslides, especially the evolution, were correlated with these historical events. The seismogenic Kangshi
Taipei Lake illustrates the activity of the JSF in the most recent event. Furthermore, a recent borehole drilled in the Jinshan Delta resulted in an unconformable contact between the Oligocene Wuchihshan Formation and recent alluvial gravel deposits at $551.6 \mathrm{~m}$ below the surface (Lin, 2005). Borehole logs show that the gravel deposits occurred uninterrupted from the ground surface until $551.6 \mathrm{~m}$, and rocks of the Wuchihshan Formation were recorded below $551.6 \mathrm{~m}$. The borehole is only approximately $300 \mathrm{~m}$ from the inferred fault line trace (Fig. 5). This contact relationship implies an association between basin subsidence and regional normal faulting. Normal faulting suggested at least $880 \mathrm{~m}$ of stratigraphic separation of throw in this area, as determined using borehole log information and regional stratigraphic correlation.

Overall, the present findings, in addition to previous studies on regional geology, geophysical observations, and recent tectonic setting interpretations (Wang, 1999; Huang, 1988; Hsiao, 1997; Hsiao et al., 1998; Lin, 2005), highlight the normal faulting activities in Jinshan. Moreover, the observed morphological discontinuities suggest that normal faulting may have cut through and truncated the volcanic cone. Thus, a fault scarp was formed, which itself is a morphological discontinuity (Fig. 13). The normal faulting process created a steeper slope and fractured the nearby rocks. The normal faulting, which cut through the volcanic and sedimentary rocks by high dipping angle, will create a steep slope at the toe region. Meanwhile, the strata discontinuity plane dipping to the same direction has a lower dip angle. The phenomena will generate a so-called "slope daylight" region (e.g., Yeh et al., 2017) and will create an unstable/hazardous region, as illustrated in Fig. 13 and shown in Fig. 12, where the maximum elevation difference is situated near the toe of the slope. The continuously activated normal faulting may furthermore create the daylight of the slope as the evidence of the exposed sediment rocks in the upslope regions within the two landslides. The weakening of rocks, in addition to the morphological discontinuities, induced slope instability in the scarp along the fault. Furthermore, successive faulting events enlarged the sliding area and modified the form of the overlying accumulated deposits. The combined actions of the elevation differences between the scarp and landslides along the active normal fault promoted the removal of the colluvium near the toe. As the normal faulting reactivated continuously, one half-graben, the Jinshan Delta, is thus formed allowing accumulation of fluvial and landslide deposits. The eroded material consequently formed a large alluvial delta at the outlet of the main stream (Fig. 5). The overall landform and structural evolution of the landslides are proposed and schematically shown in Fig. 13. 


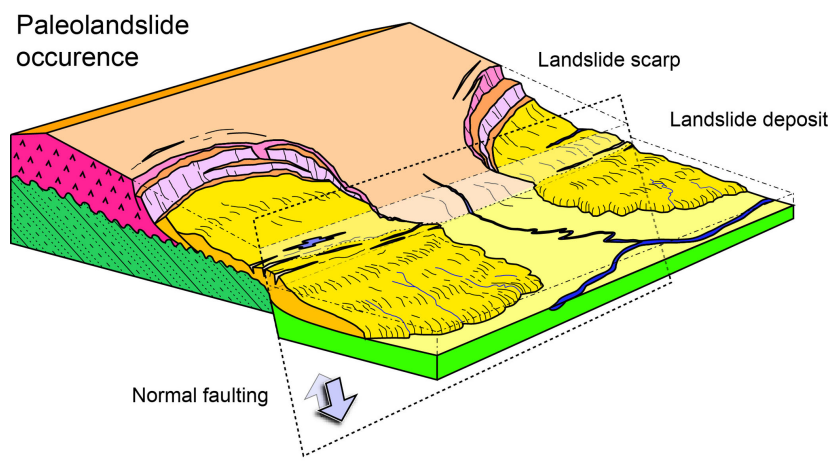

ing valuable insights into the morphological interactions: (1) normal faulting may have triggered the main landslides, (2) erosion near the fault scarp enhanced the transportation of colluvium and river incision, and (3) gully incision indicated that the main landslides may have resulted from old landslide events. New tectonic activities because of normal faulting will likely result in the reactivation of the existing landslides posing life-threatening situations, particularly if the slope toe is being eroded by alluvial processes transporting sediments downstream and by graben subsidence daylighting the dip slope and reactivating landslide. The potential multiple geological hazards as anticipated by the proposed geomorphological evolution because of the fault activity are worthy of further investigation for hazard mitigation purposes.

Data availability. Lidar topography obtained from the project supported by the Central Geological Survey, Ministry of Economic Affairs, Taiwan R.O.C. UAS data were acquired by the authors. Data can be obtained upon request from the correspondence author (epidote@ntut.edu.tw).

Competing interests. The authors declare that they have no conflict of interest.

Special issue statement. This article is part of the special issue "The use of remotely piloted aircraft systems (RPAS) in monitoring applications and management of natural hazards". It is a result of the EGU General Assembly 2016, Vienna, Austria, 17-22 April 2016.

Acknowledgements. We thank Fu-Shu Jeng of National Taiwan University for revising the first draft of this paper and Jian-Cheng Lee and Su-Ching Chou of the Institute of Earth Sciences, Academia Sinica for their constructive comments and assistance. We also thank Christopher Fong for providing technical advice. This study was partly supported by the Central Geological Survey, Ministry of Economic Affairs, Taiwan R.O.C.; Tatun thematic project from the Institute of Earth Sciences, Academia Sinica; and Ministry of Science and Technology, Taiwan R.O.C.

Edited by: Yuichi S. Hayakawa

Reviewed by: two anonymous referees

The presented UAS technology and lidar data reveal the relevance of high-resolution digital surface images, namely DTMs, DSMs, and true 3-D models, for effective surveys of obscure old landslides in a volcanic region. To investigate the morphological evolution, procedures for paleolandform reconstruction were proposed, based on the concept of the envelope surface, according to relict topography from the Tatun volcano group in northern Taiwan. This analysis was extended to geomorphic applications, such as estimating the cut-and-fill volume and interpreting fluvial processes. The study area in the Tatun volcano group provides the follow- 
Bucci, F., Santangelo, M., Cardinali, M., Fiorucci, F., and Guzzetti, F.: Landslide distribution and size in response to Quaternary fault activity: the Peloritani Range, NE Sicily, Italy, Earth. Surf. Proc. Land., 41, 711-720, https://doi.org/10.1002/esp.3898, 2016.

Bühler, Y., Adams, M. S., Bösch, R., and Stoffel, A.: Mapping snow depth in alpine terrain with unmanned aerial systems (UASs): potential and limitations, The Cryosphere, 10, 10751088, https://doi.org/10.5194/tc-10-1075-2016, 2016.

Chan, Y. C., Chang, K. J., Chen, R. F., and Liu, J. K.: Topographic changes revealed by airborne LiDAR surveys in regions affected by the 2009 Typhoon Morakot, southern Taiwan, Western Pacific Earth Sciences, 12, 67-82, 2012.

Chang, K. J., Taboada, A., and Chan, Y. C.: Geological and morphological study of the Jiufengershan landslide triggered by the ChiChi Taiwan earthquake, Geomorphology, 71, 293-309, 2005.

Chang, K. J., Taboada, A., Chan, Y. C., and Dominguez, S.: Postseismic surface processes in the Jiufengershan landslide area, 1999 Chi-Chi earthquake epicentral zone, Taiwan, Eng. Geol., 86, 102-117, 2006.

Chang, K. J., Chan, Y. C., Chen, R. F., and Hsieh, Y. C.: Evaluation of Tectonic Activities Using LiDAR Topographic Data: The Nankan Lineament in Northern Taiwan, Terr. Atmos. Ocean. Sci., 21, 463-476, https://doi.org/10.3319/TAO.2009.11.17.01(TH), 2010.

Chen, C. T., Hu, J. C., Lu, C. Y., Lee, J. C., and Chan, Y. C.: Thirtyyear land elevation change from subsidence to uplift following the termination of groundwater pumping and its geological implications in the Metropolitan Taipei Basin, Northern Taiwan, Eng. Geol., 95, 30-47, 2007.

Chen, C. T., Lee, J. C., Chan, Y. C., and Lu, C. Y.: Growth Normal Faulting at the Western Edge of the Metropolitan Taipei Basin since the Last Glacial Maximum, Northern Taiwan, Terr. Atmos. Ocean. Sci., 21, 409-428, https://doi.org/10.3319/TAO.2009.11.13.01(TH), 2010.

Chen, R. F., Chan, Y. C., Angelier, J., Hu, J. C., Huang, C., Chang, K. J., and Shih, T. Y.: Large earthquake-triggered landslides and mountain belt erosion: The Tsaoling case, Taiwan, C. R. Geosci., 337, 1164-1172, 2005.

Chen, R. F., Chang, K. J., Angelier, J., Chan, Y. C., Deffontaines, B., Lee, C. T., and Lin, M. L.: Topographical changes revealed by high-resolution airborne LiDAR data: The 1999 Tsaoling landslide induced by the Chi-Chi earthquake, Eng. Geol., 88, 160172, 2006.

Chen, J., Li, K., Chang, K. J., Sofia, G., and Tarolli, P.: Open-pit mining geomorphic feature characterization, Int. J. Appl. Earth. Obs., 42, 76-86, 2015.

Chen, W. S., Yang, C. C., Yang, H. C., and Liu, J. K.: Volcanic landform and sequences of the Tatun Volcanoes, Bull. Centr. Geol. Surv., 16, 99-124, 2003 (in Chinese).

Clayton, C. R. I., Simons, N. E., and Matthews, M. C.: Site Investigation: A Handbook for Engineers, Halsted Press, New York, USA, 423 pp., 1982.

de Vries, B. W., Kerle, N., and Petley, D.: Sector collapse forming at Casita volcano, Nicaragua, Geology, 28, 167-170, https://doi.org/10.1130/0091-7613(2000)28, 2000.

Deffontaines, B., Chang, K. J., Champenois, J., Fruneau, B., Pathier, E., Hu, J. C., Lu, S. T., and Liu, Y. C.: Active interseismic shallow deformation of the Pingting terraces (Longitudinal Valley - Eastern Taiwan) from UAV high-resolution topographic data com- bined with InSAR time series, Geomat. Nat. Haz. Risk., 8, 120136, https://doi.org/10.1080/19475705.2016.1181678, 2016.

Densmore, A. L., Anderson, R. S., McAdoo, B. G., and Ellis, M. A.: Hillslope Evolution by Bedrock Landslides, Science, 275, 369372, https://doi.org/10.1126/science.275.5298.369, 1997.

Fernandez-Galarreta, J., Kerle, N., and Gerke, M.: UAV-based urban structural damage assessment using object-based image analysis and semantic reasoning, Nat. Hazards Earth Syst. Sci., 15, 10871101, https://doi.org/10.5194/nhess-15-1087-2015, 2015.

Giordan, D., Manconi, A., Facello, A., Baldo, M., dell'Anese, F., Allasia, P., and Dutto, F.: Brief Communication: The use of an unmanned aerial vehicle in a rockfall emergency scenario, Nat. Hazards Earth Syst. Sci., 15, 163-169, https://doi.org/10.5194/nhess-15-163-2015, 2015.

Glenn, N. F., Streutker, D. R., Chadwick, D. J., Thackray, G. D., and Dorsch, S. J.: Analysis of LiDAR-derived topographic information for characterizing and differentiating landslide morphology and activity, Geomorphology, 73, 131-148, 2006.

Gritzner, M., Marcus, A., Aspinall, R., and Custer, S.: Assessing landslide potential using GIS, soil wetness modeling and topographic attributes, Payette River, Idaho, Geomorphology, 37, 149-165, 2001.

Guzzetti, F., Mondini, A. C., Cardinali, M., Fiorucci, F., Santangelom, M., and Chang, K. T.: Landslide inventory maps: New tools for an old problem, Earth Sci. Rev., 112, 42-66, 2012.

Ho, T. S.: A synthesis of the geologic evolution of Taiwan, Tectonophysics, 125, 1-16, 1986.

Hsiao, L. Y.: Late Cenozoic structures off northeastern Taiwan, MS thesis, National Taiwan University, Taipei, Taiwan, 62 pp., 1997 (in Chinese).

Hsiao, L. Y., Lin, K. A., Teng, L. S., and Huang, S. T.: Structural characteristics of the southern Taiwan - Sinzi folded zone, Petrol. Geol. Taiwan, 32, 133-154, 1998 (in Chinese with English abstract).

Hsieh, Y. C., Chan, Y. C., and Hu, J. C.: Digital Elevation Model Differencing and Error Estimation from Multiple Sources: A Case Study from the Meiyuan Shan Landslide in Taiwan, Remote Sens.-Basel, 8, 1-20, https://doi.org/10.3390/rs8030199, 2016.

Huang, C. S.: Explanatory text of the geologic map of Taiwan, 1:50000, sheet 4, Taipei, Central Geological Survey, Ministry of Economics Affaires: Taipei, Taiwan, 57 pp., 1988 (in Chinese).

Huang, M. J. and Chang, K. J.: Unmanned Aerial Vehicle (UAV) associated DTM quality evaluation and application, Mag. Chinese Inst. Civil Hydraulic Eng., 41, 52-58, 2014 (in Chinese with English abstract).

Huang, S. Y., Rubin, C. M., Chen Y. G., and Liu, H. C.: Prehistoric earthquakes along the Shanchiao fault, Taipei Basin, northern Taiwan, J. Asian Earth Sci., 31, 265-276, 2007.

IAEG Commission on Landslides: Suggested nomenclature for landslides, in: Bulletin of the International Association of Engineering Geology, Springer, Paris, 41, 13-16, 1990.

Lin, C. C.: Annual Report of Central Geological Survey, Central Geological Survey, Ministry of Economics Affaires: Taipei, Taiwan, 154 pp., 2005 (in Chinese).

Malavieille, J., Lallemand, S. E., Dominguez, S., Deschamps, A., Lu, C.-Y., Liu, C.-S., Schnurle, P., and ACT Scientific Crew: Arccontinent collision in Taiwan: New marine observations and tectonic evolution, in: Geology and Geophysics of an Arc-Continent collision, Taiwan, Republic of China, edited by: Byrne, T. B. and 
Liu, C.-S., Geol. S. Am. S., Boulder, Colorado, USA, 358, 187211, 2002.

Norini, G. and Lagmay, A. M. F.: Deformed symmetrical volcanoes, Geology, 33, 605-608, https://doi.org/10.1130/G21565.1, 2005.

Reid, M. E.: Massive collapse of volcano edifices triggered by hydrothermal pressurization, Geology, 32, 373-376, https://doi.org/10.1130/G20300.1, 2004.

Reid, M. E., Sisson, T. W., and Brien, D. L.: Volcano collapse promoted by hydrothermal alteration and edifice shape, Mount Rainier, Washington, Geology, 29, 779-782, https://doi.org/10.1130/0091-7613(2001)029, 2001.

Shieh, Y. T.: The paleogeography of the ancient Taipei Lake in Kanghsi Period, J. Geogr. Sci., 27, 85-95, 2000.

Santangelo, M., Gioiac, D., Cardinalia, M., Guzzettia, F., and Schiattarella, M.: Landslide inventory map of the upper Sinni River valley, Southern Italy, J. Maps, 11, 444-453, 2015a.

Santangelo, M., Marchesini, I., Bucci, F., Cardinali, M., Fiorucci, F., and Guzzetti, F.: An approach to reduce mapping errors in the production of landslide inventory maps, Nat. Hazards Earth Syst. Sci., 15, 2111-2126, https://doi.org/10.5194/nhess15-2111-2015, 2015b.

Scheingross, J. S., Minchew, B. M., Mackey, B. H., Simons, M., Lamb, M. P., and Hensley, S.: Fault-zone controls on the spatial distribution of slow-moving landslides, Geol. Soc. Am. Bull., 125, 473-489, https://doi.org/10.1130/B30719.1, 2013.

Shyu, J. B. H., Sieh, K., Chen, Y.-G., and Liu, C.-S.: Neotectonic architecture of taiwan and its implications for future large earthquakes, J. Geophys. Res., 110, B08402, https://doi.org/10.1029/2004JB003251, 2005.

Song, S. R., Tsao, S., and Lo, H. J.: Characteristics of the Tatun volcanic eruptions, north Taiwan: implications for a cauldron formation and volcanic evolution, J. Geol. Soc. China, 43, 361-378, 2000.

Staley, D. M., Wasklewicz, T. A., and Blaszczynski, J. S.: Surficial patterns of debris flow deposition on alluvial fans in Death Valley, CA using airborne laser swath mapping data, Geomorphology, 74, 152-163, 2006.

Strecker, M. R. and Marret, R.: Kinematic evolution of fault ramps and its role in development of landslides and lakes in the northwestern Argentine Andes, Geology, 27, 307-310, 1999.

Suppe, J.: Mechanics of mountain building in Taiwan, Memo. Geol. Soc. China, 4, 67-89, 1981.

Teng, L. S.: Extensional collapse of the northern Taiwan mountain belt, Geology, 24, 949-952, 1996.
Teng, L. S., Lee, C. T., Peng, C. H., Chen, W. F., and Chu, C. J.: Origin and geological evolution of the Taipei basin, Northern Taiwan, Western Pacific Earth Sciences, 1, 115-142, 2001.

Tokarczyk, P., Leitao, J. P., Rieckermann, J., Schindler, K., and Blumensaat, F.: High-quality observation of surface imperviousness for urban runoff modelling using UAV imagery, Hydrol. Earth Syst. Sci., 19, 4215-4228, https://doi.org/10.5194/hess-19-42152015, 2015.

Tsai, Y. B.: A study of disastrous earthquakes in Taiwan, 16831895, Bull. Inst. Earth Sci., Acad. Sin., 5, 1-44, 1985.

Tsao, S.: K-Ar age determination of volcanic rocks from the Tatun Volcano Groupe, Bull. Centr. Geol. Surv., 9, 137-154, 1994 (in Chinese).

Varnes, D. J.: Slope movement types and processes, in: Landslides and engineering practice, edited by: Eckel, E. B., HRB, National Research Council, Washington D.C., USA, 29, 20-47, 1978.

Wang, K. L., Chung, S. L., Chen, C. H., Shinjo, R., Yang, T. F., and Chen, C. H.: Post-collisional magmatism around northern Taiwan and its relation with opening of the Okinawa Trough, Tectonophysics, 308, 363-376, 1999.

Wang, W. S.: Volcanic geology and fission track datings of the Tatun volcano group, MS thesis, National Taiwan University, Taipei, Taiwan, 154 pp., 1989 (in Chinese).

Wei, K., Chen, Y. G., and Lu, T. K.: Sedimentary history of the Taipei Basin with constraints from thermoluminescence dates, Journal of the Geological Society of China, 41, 109-125, 1998.

Yeh, C. H., Chan, Y. C., Chang, K. J., Lin, M. L., and Hsieh, Y. C.: Derivation of strike and dip in sedimentary terrain using 3-D image interpretation based on airborne LiDAR data, Terr. Atmos. Ocean. Sci., 25, 775-790, 2014.

Yeh, C. H., Lin, M. L., Chan, Y. C., Chang, K. J., and Hsieh, Y. C.: Dip-slope mapping of sedimentary terrain using polygon autotracing and airborne LiDAR topographic data, Eng. Geol., 222, 236-249, 2017.

Yu, S. B., Chen, H. Y., Kuo, L. C., Hou, C. S., and Lee, J. F.: A study on the fault activities of the Taipei Basin, in: Special Issue for the Subsurface Geology and Engineering Environment of the Taipei Basin, edited by: Chen, C. H., Central Geological Survey, MOEA, Taipei, 227-251, 1999.

Yu, Y. H.: Pi Hai Chi You (travel notes in Taiwan), Economic research institute, Bank of Taiwan, Taipei, Taiwan, available at: http://www.guoxue123.com/tw/01/044/004.htm (last access: 26 February 2018), 1959 (The original notes were printed in 1697, in Chinese). 